\title{
Catalytic Activity for Dye Degradation and Characterization of Silver/Silver Oxide Nanoparticles Green Synthesized by Aqueous Leaves Extract of Phoenix Dactylifera L.
}

\section{Salah Laouini}

Centre Universitaire d'El Oued

Abderrhmane Bouafia ( $\sim$ abdelrahmanebouafia@gmail.com )

Centre Universitaire d'El Oued

Mohammed Tedjani

Centre Universitaire d'El Oued

\section{Research Article}

Keywords: silver/silver oxide nanoparticles, Phoenix Dactylifera L, Silver nitrate AgNO3, Green Synthesis, Catalytic Activity, dye degradation.

Posted Date: January 7th, 2021

DOl: https://doi.org/10.21203/rs.3.rs-139856/v1

License: (c) (1) This work is licensed under a Creative Commons Attribution 4.0 International License.

Read Full License 


\title{
Catalytic Activity for Dye Degradation and Characterization of Silver/Silver Oxide Nanoparticles Green Synthesized by Aqueous Leaves Extract of Phoenix Dactylifera L.
}

\author{
Salah Eddine Laouini ${ }^{1}$, Abderrhmane Bouafia ${ }^{1,{ }^{*}}$ and Mohammed Laid Tedjani- ${ }^{1}$ \\ ${ }^{1}$ Department of Process Engineering and Petrochemistry, Faculty of Technology, University of \\ Echahid Hamma Lakhdar El Oued, 39000 El-Oued, Algeria
}

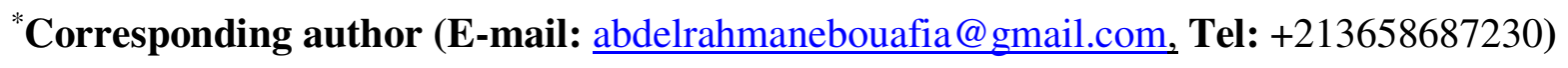

\begin{abstract}
In this study, green synthesis of silver/silver oxide nanoparticles was successfully prepared from Phoenix Dactylifera $L$ aqueous leaves extract. The effect of different volume ratios (\% v/v) (Plant extract / Precursor) on the nanoparticles silver /silver oxide nanoparticles formation, optical properties, and catalytic activity for dye degradation was studied. The obtained $A g / A_{2} \mathrm{O}$ nanoparticles were characterized using various techniques, such as UV-Visible, FT-IR, XRD, SEM for this purpose. The UV-Vis spectrum shows the absorption at $430 \mathrm{~nm}$ associated with $\mathrm{Ag} / \mathrm{Ag}_{2} \mathrm{O}$ NPs. The optical bandgap values were found to be in the range of 3.22 to $4.47 \mathrm{eV}$ for the direct bandgap and 3.73 to $5.23 \mathrm{eV}$ for the indirect bandgap. The functional groups present in plant extracts were studied by FTIR. XRD confirmed the crystalline nature of $\mathrm{Ag} / \mathrm{Ag}_{2} \mathrm{O} \mathrm{NP}$, and its average particle size was between $28.66-39.40 \mathrm{~nm}$. SEM showed that the green synthesized silver/silver oxide nanoparticles have a spherical shape. The purpose of this study, it highlights the high catalytic activity for dye degradation of $\mathrm{Ag} / \mathrm{Ag}_{2} \mathrm{O}$ NPs green synthesized. As a result, the use of Phoenix Dactylifera $L$ aqueous leaves extract offers a cost-effective and eco-friendly method.
\end{abstract}

Keywords: silver /silver oxide nanoparticles; Phoenix Dactylifera L; Silver nitrate $\mathrm{AgNO}_{3}$; Green Synthesis; Catalytic Activity; dye degradation. 


\section{Introduction}

Nanotechnology is a relatively new scientific field that adopts engineering nanoparticles from different materials physically, chemically and biologically ${ }^{1}$. Nanotechnology is also defined as "the creation and use of structures, devices and systems that are characterized by their distinct and varied characteristics and infinitesimal size, in general to deal with particles within the range of Size $<100$ nanometers ${ }^{2}$, the world is witnessing an industrial revolution in nanoscience, which enabled it to convert negative nanostructures into positive and productive nanostructures. Researchers and scientists have predicted the great role that nanotechnology will play in playing a great role in the development of the developing world, so that the abundance of new ways and means, and revolutionary, which contributed to advances such as energy storage and transport, medicine and pharmacy ${ }^{3}$.

Green synthesis is a modern area of biotechnology that is economically and environmentally beneficial as an alternative to chemical and physical methods that contain part of the hazard to the environment. Because in this method, biologically safe, non-toxic, and environmentally friendly natural reagents ${ }^{4}$, Mentha pulegium $L^{5}$, Artemisia ${ }^{6}$, Moringa Oleifera ${ }^{7}$, Phoenix dactylifera $L^{8}$, and others are used in the biosynthesis of metal oxide nanoparticles ${ }^{9,10}$. The researchers used widely available plant extracts in nature in the green synthesis of metal oxide nanoparticles. It is also known as "vital plants" because of its speed, environmental efficiency, and low cost. It has a high ability to absorb minerals while maintaining safety levels ${ }^{11}$. These methods include microbes such as fungi, bacteria, algae, and viruses as reducing agents ${ }^{12-15}$. It is considered environmentally friendly because during the biosynthesis of nanoparticles the resulting toxic chemicals are eliminated as they break down with the help of enzymes present in microbes.

In recent years, research has been conducted in the field of nanotechnology that uses green plant materials and extracts for the biosynthesis of metal oxide nanoparticles without adding any external chemical substances that cause environmental pollution. The synthesis of metal nanoparticles is accomplished by a green method, using different plant fractions as reducing agents and caulking agents. Among the many different metal nanoparticles that have been studied, the precious metal silver oxide hopes to be used in various fields due to its unique characteristics, so it occupies a large position in all nanomaterials research. Its characteristics are sensing, photoelectric, catalysis and drug delivery ${ }^{16}$. 
In this study, green synthesized silver/silver oxide nanoparticles by Phoenix Dactylifera $L$ aqueous leaf extract, was investigated. Characterizations of the obtained nanoparticles were analyzed using standard techniques such as UV-Vis, FT-IR, XRD, and SEM. In addition, the effect of different volume ratios $(\mathrm{v} / \mathrm{v})$ (plant extract / precursor) on their optical properties and catalytic activity for dye degradation were evaluated.

\section{Materials and Methods}

\subsection{Materials}

Silver nitrate $\mathrm{AgNO}_{3}$ obtained from (VTRS) Laboratory, Leaves of Phoenix Dactylifera $L$ were harvested from El Oued south east of Algiers.

\subsection{Preparation of plant leaf extract}

Leaves of Phoenix Dactylifera $L$ were washed by distilled water, dry for 12 days in a shade place at room temperature, and then crush to obtain a fine powder. Has been put 10 grams of powdered Phoenix Dactylifera $L$ leaves and $100 \mathrm{ml}$ of distilled water into a $250 \mathrm{ml}$ glass beaker to prepare the extract. The mixture was stirred stably at room temperature for one day. After that, the extract was filtered with filter paper (Whatman No: 42) and stored in a glass container at $4^{\circ} \mathrm{C}$ for further use $^{6,8,17}$.

\subsection{Biosynthesis of silver/silver oxide nanoparticles}

The $\mathrm{Ag} / \mathrm{Ag}_{2} \mathrm{O}$ NPs were synthesized by adding a different volume ratios (v /v) (plant extract / precursor) $\left(1 / 30,1 / 40\right.$ and 1/50), $1 \mathrm{ml}$ of leaf extract to $50 \mathrm{ml}$ of $1 \mathrm{mM} \mathrm{AgNO}_{3}$ aqueous solution in a $250 \mathrm{ml}$ Erlenmeyer flask stirring $150 \mathrm{rpm}$ at room temperature for 2 hours, the bioreduction of $\mathrm{Ag}^{+}$to $\mathrm{Ag}{ }^{\circ}$ was confirmed by a color change to brown after 5 minutes.

\subsection{Characterisation of silver/silver oxide nanoparticles}

\subsection{1. $U V$-visible spectroscopy}

The biosynthesis of $\mathrm{Ag} / \mathrm{Ag}_{2} \mathrm{O}$ NPs were analyzed by using UV-vis spectrometry (shimadzu -1800), the measurement were recorded at the temperature in wavelength region of 300 to $900 \mathrm{~nm}$. The stability of formation of $\mathrm{Ag} / \mathrm{Ag}_{2} \mathrm{O}$ NPs was followed by UV-vis spectrometry using a quartz cells and distilled water as blank solution. 


\subsubsection{FTIR spectroscopy}

Fourier transform infrared (FTIR) measurements of leaf extract and of green synthesis $\mathrm{Ag} / \mathrm{Ag}_{2} \mathrm{O}$ NPs were performed by (Nicolet iS5, Thermo Fisher Scientific), to identify the functional groups in carried out in the range of 4000 to $400 \mathrm{~cm}-1$.

\subsubsection{X-Ray Diffraction (XRD)}

The crystalline structure of the synthesized NPs was obtained using X-ray diffractometer (Rigaka Miniflex 600) and CuK radiation with a wavelength of $0,15406 \mathrm{~nm}$ in the angular range $10^{\circ}<$ $2 \theta<80^{\circ}$

\subsubsection{Scanning Electron Microscopy (SEM)}

The shape and morphology of the synthesis $\mathrm{Ag} / \mathrm{Ag}_{2} \mathrm{O}$ NPs was confirmed by using (SEMTESCAN VEGA 3) at accelerating voltage of $10 \mathrm{KV}$.

\subsection{Catalytic Activity for Dye Degradation}

\subsubsection{Catalytic degradation of Congo red}

The silver nanoparticles obtained by green method used for reducing of Congo red in the presence of sodium borohydride $\left(\mathrm{NaBH}_{4}\right)$ at room temperature. Firstly, $2.5 \mathrm{ml}$ of diluted Congo red was analysis ultraviolet visible, and appeared the peak occur at $\lambda_{\max }=488 \mathrm{~nm}$. The catalytic reaction was calculated to be conducted in all experiments. To investigate the catalytic effect of the biosynthesized silver nanoparticles, $\mathrm{NaBH}_{4}$ solution $\left(10-^{2} \mathrm{M}\right)$ (considered a reducing agent) was added to the Congo red solution $\left(10^{-4} \mathrm{M}\right)$, which was followed by the addition of biosynthesized silver nanoparticles $(10 \mathrm{mg} / \mathrm{l})$, and adjust the $\mathrm{PH}$ of the reaction and completed the reaction at volume of $5 \mathrm{ml}$. The degradation process was observed spectrophotometrically in a wavelength range of 250-900 $\mathrm{nm}$ at $10 \mathrm{mn}$ to $60 \mathrm{mn}$. The decolourization process was observed as a decline in the absorbance intensity $\left(\lambda_{\max }\right)$ of the solution. The Experiments showed to examine the catalytic efficacy of the biosynthesized silver nanocatalysts.

\subsubsection{Catalytic degradation of Methylene blue}

The effect of $\mathrm{Ag} / \mathrm{Ag}_{2} \mathrm{O}$ NPs on degradation of methylene blue was estimated in the same way to the reduction of Congo red. The reaction composed $3 \mathrm{ml}$ of methylene blue $\left(2.10^{-6} \mathrm{~mol} / \mathrm{l}\right)$ and $3 \mathrm{ml}$ of methylene blue $\left(2.10^{-6} \mathrm{~mol} / \mathrm{l}\right)$. The above reaction was added to $\mathrm{NaBH}_{4}$ solution $2.25 \mathrm{ml}\left(6.10^{-6}\right.$ $\mathrm{mol} / \mathrm{l})$, and $150 \mu \mathrm{l}$ (80.85 mg/l Ag/ $\mathrm{Ag}_{2} \mathrm{O}$ NPs on suspension). The degradation of methylene blue controlled at different time by optical absorbance at $611 \mathrm{~nm}$ and $663 \mathrm{~nm}$. 


\section{Results and discussion}

\subsection{Characterization of silver/silver oxide nanoparticles}

Preliminary studies suggest that phytochemical screening of Phoenix Dactylifera L Leaves extract indicates the presence of polyphenols, flavonoids, and condensed tannins ${ }^{18}$.

\subsubsection{UV-visible Spectroscopy}

The colloidal solution of the as-prepared $\mathrm{Ag} / \mathrm{Ag}_{2} \mathrm{O}$ and the plant extract were analyzed using UVVis spectroscopy (Figure 1). Accordingly, the plant extract spectrum has exhibited two peaks at 275 and $320 \mathrm{~nm}$. Meanwhile the $\mathrm{Ag} / \mathrm{Ag}_{2} \mathrm{O}$ spectra revealed on a common peak in all the samples $(1 / 30,1 / 40,1 / 50)$ situated at $430 \mathrm{~nm}$. This peak corresponds to the characteristic surface plasmon resonance absorption band of $\mathrm{Ag} / \mathrm{Ag}_{2} \mathrm{O}{ }^{19-21}$. 


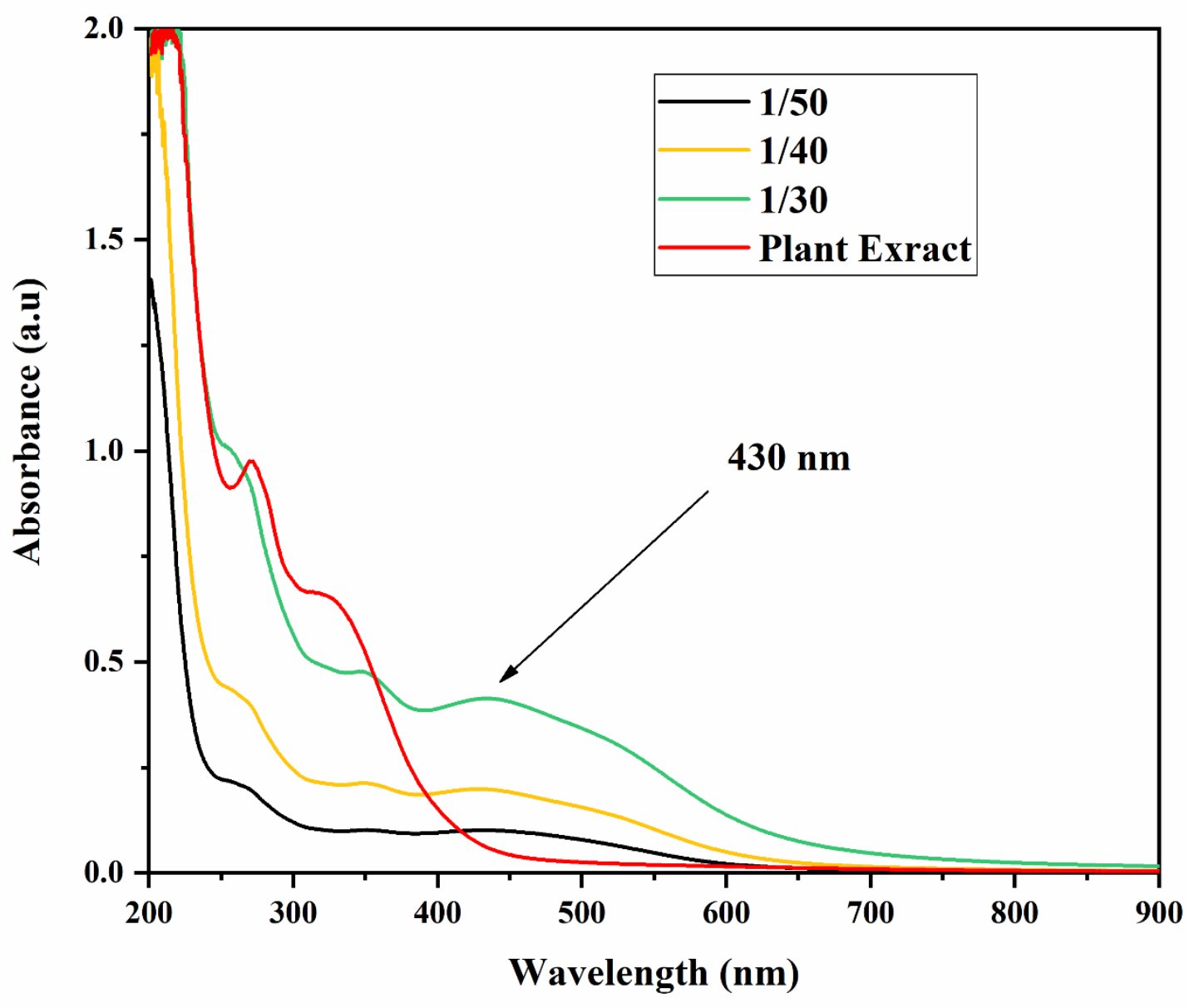

Figure $1 \mathrm{UV}$-visible Spectrum of $\mathrm{Ag}_{\mathrm{A}} \mathrm{Ag}_{2} \mathrm{O}$ and plant Extract.

\subsubsection{Estimation of the optical band gap:}

Generally, the optical band gap of a semiconductor can be determined by plotting absorption coefficient verses the photon energy which could be estimated using the Tauc's formula (Equation (1)) ${ }^{22}$ :

$$
(\alpha h v)=K\left(h v-E_{g}\right)^{n}
$$

where $h v$ is the incident photon energy, $\alpha$ is the absorption coefficient, $K$ is a constant, $E_{g}$ is the optical band gap in electron-volts $(\mathrm{eV})$ and $n$ is an exponent that can take different values depending on the nature of the electronic transition, i.e.; $n=2$ for direct transition, and $n=1 / 2$ for indirect transition as shown in Figure 2 and Figure $3^{23,24}$.

The estimated values of the direct and indirect transitions of the samples are listed in . 


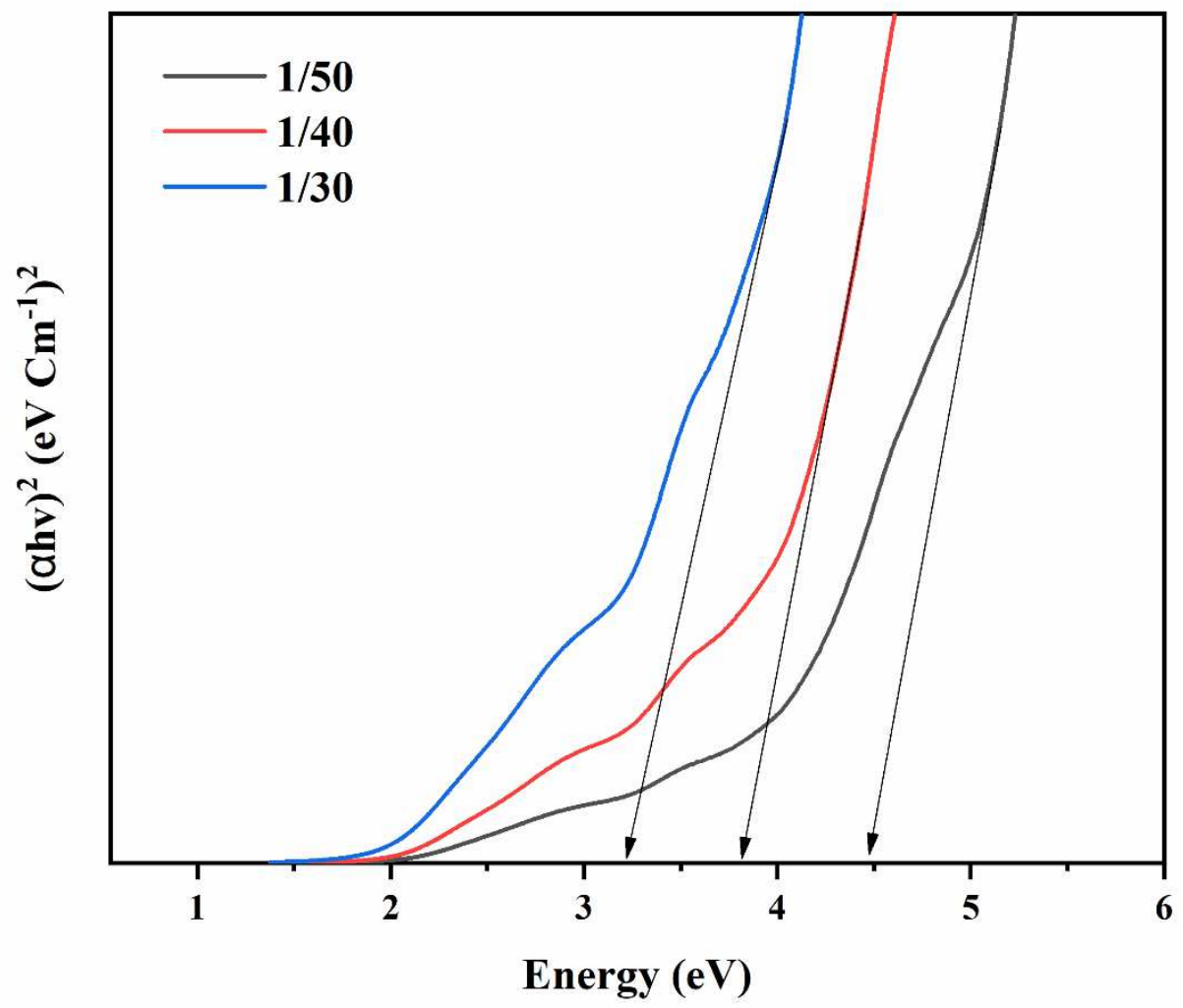

Figure 2 Determination of optical energy gap for direct transition using Tauc's method. 


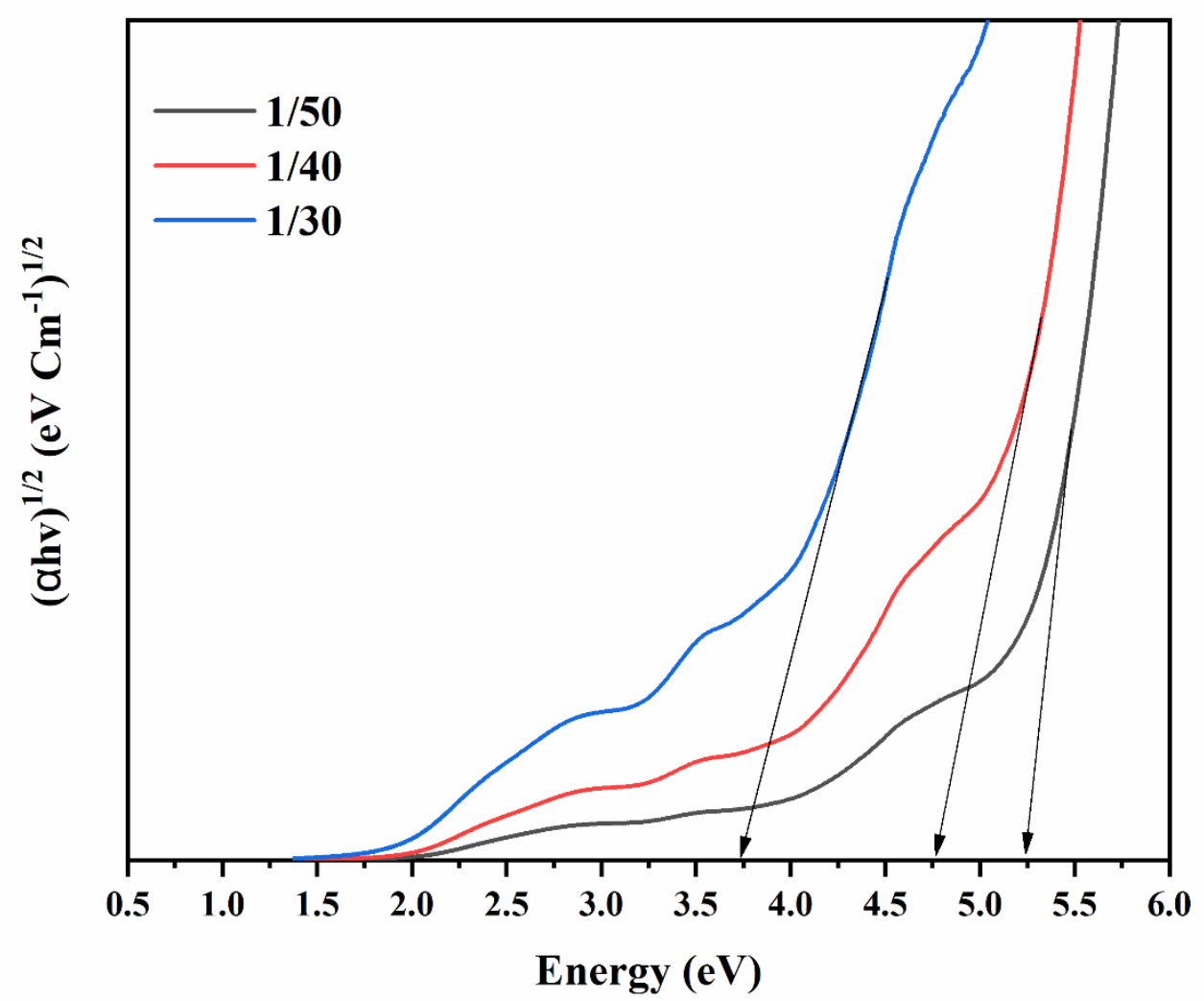

Figure 3 Determination of optical energy gap for indirect transition using Tauc's method.

\subsubsection{Estimation of the Urbach energy:}

The Urbach energy designates the width of the band tails of the localized states. Urbach energy $E u$, is determined from the slope of the linear part of the plot of $\ln a$ versus photon energy (Figure 4) ${ }^{25}$.

$$
\ln a=\frac{h v}{E u}+\text { constant }\left(\ln a_{0}\right)
$$

The results of the estimated Urbach energy values of the samples are listed in Table 1. 


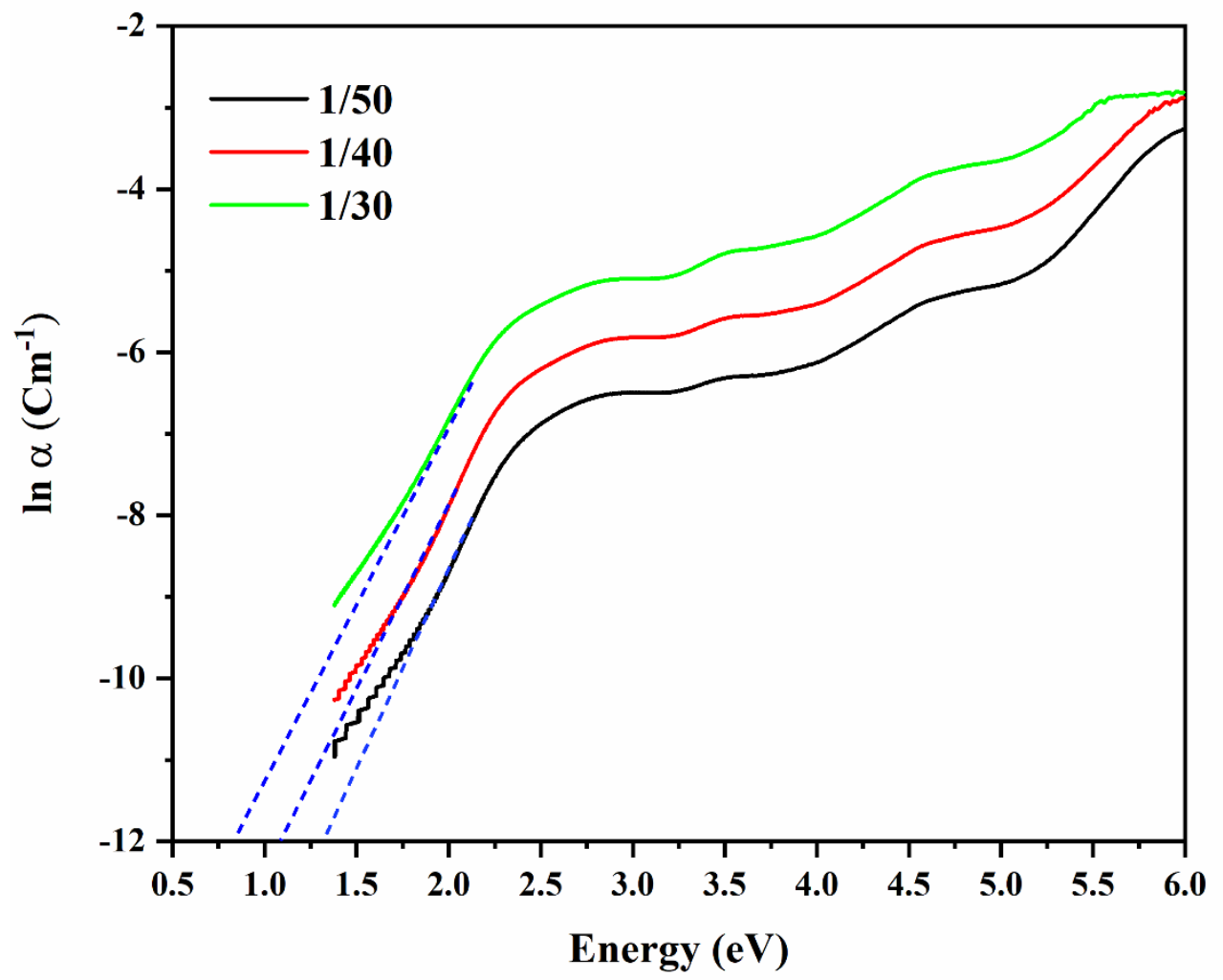

Figure 4 Calculation of Urbach energy for the synthesized $\mathrm{Ag}_{\mathrm{Ag}} \mathrm{O}$

Table 1 The values of direct band gap, indirect band gap and urbach energy of the biosynthesized $\mathrm{Ag} / \mathrm{Ag}_{2} \mathrm{O}$.

\begin{tabular}{cccc}
\hline Volume ratios & $\begin{array}{c}\text { Direct Optical } \\
\text { band gap } \\
(\mathrm{eV})\end{array}$ & $\begin{array}{c}\text { Indirect Optical } \\
\text { band gap } \\
(\mathrm{eV})\end{array}$ & $\begin{array}{c}\text { Urbach energy } \\
(\mathrm{eV})\end{array}$ \\
\hline $1 / 50$ & 3.22 & 3.73 & 0.22 \\
$1 / 40$ & 3.80 & 4.78 & 0.20 \\
$1 / 30$ & 4.47 & 5.23 & 0.23 \\
\hline
\end{tabular}

\subsubsection{Fourier Transform Infrared (FTIR) spectroscopy}

The FTIR analysis was carried out to identify the potential presence of reducing and stabilizing biomolecules in the Phoenix Dactylifera $L$ extract. The resultant FTIR spectrum (Figure 5) has exhibited several absorption bands that correspond to the functional groups of the biomolecules existing in the plant extract. Five main absorption peaks were observed, the broad peak centered at 
$3340 \mathrm{~cm}^{-1}$ is assigned to $\mathrm{O}-\mathrm{H}$ stretching vibrations ${ }^{6}$, the intense peak at $1650 \mathrm{~cm}^{-1}$ is due to $\mathrm{C}=\mathrm{O}$ stretching and $\mathrm{N}-\mathrm{H}$ bending vibrations of primary amides group which is commonly found in the protein ${ }^{26}$. The two peaks located at $1364 \mathrm{~cm}^{-1}$ and $1204 \mathrm{~cm}^{-1}$ are assigned to the nitro banding $\mathrm{N}$ $\mathrm{O}$ vibrations and $\mathrm{C}-\mathrm{O}-\mathrm{C}$ stretching vibrations of the aromatic ring respectively ${ }^{27}$. In addition, the peak located at $650 \mathrm{~cm}^{-1}$ corresponds to $\mathrm{C}-\mathrm{H}$ bending vibrations out of plane ${ }^{28}$.

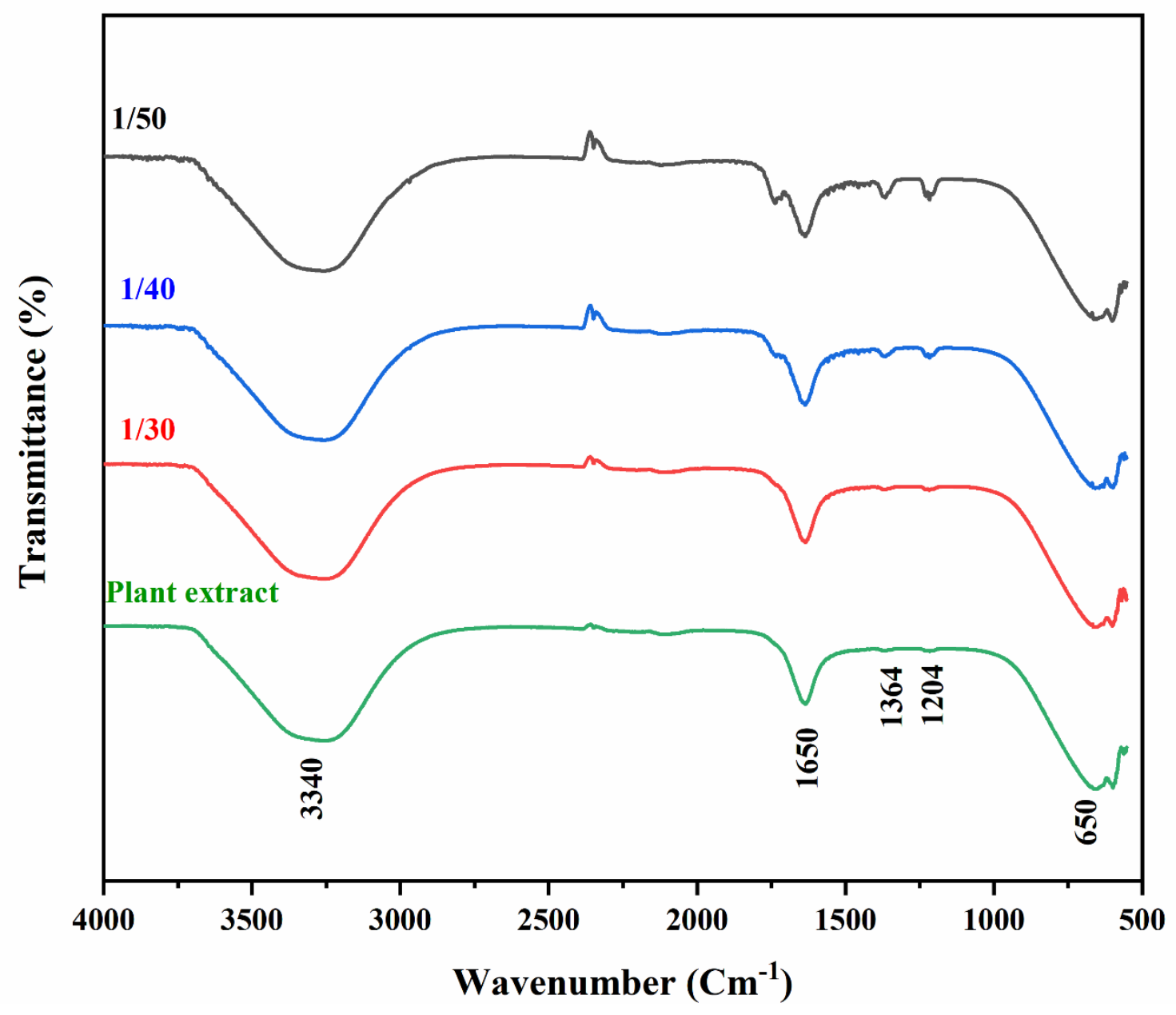

Figure 5 FTIR spectra of Phoenix Dactylifera L extract and the biosynthesized $\mathrm{Ag} / \mathrm{Ag} 2 \mathrm{O}$.

The FTIR results shows that Phoenix Dactylifera $L$ extract contain many different functional groups such as carboxyl, carbonyls, amides and phenols, which could serve as bio-reducing and capping agents for $\mathrm{Ag} / \mathrm{Ag}_{2} \mathrm{O}$ synthesis ${ }^{7}$.

\section{1..1 3.1.3.X-ray diffraction (XRD)}

The X-ray diffraction patterns of the biosynthesized $\mathrm{Ag} / \mathrm{Ag}_{2} \mathrm{O}$ nanoparticles at different volume ratios (Ag ions solution : Extract) are shown in (Figure 6). A number of Bragg reflection peaks 
were observed in all the XRD patterns located at $2 \theta$ values of $38.16^{\circ}, 44.34^{\circ}, 64.57^{\circ}$, and $77.60^{\circ}$ corresponding to (111), (200), (220), and (311) planes of pure silver based on the face-centered cubic structure (JCPDS, file No. 04-0783) ${ }^{29,30}$. Whereas the peaks at $2 \theta$ values of $26.9^{\circ}, 32.69^{\circ}$, $37.94^{\circ}, 54.9^{\circ}, 65.54^{\circ}$ and $69^{\circ}$ related to (110), (111), (200), (220), (311) and (222) planes of silver (I) oxide face-centered cubic crystalline (JCPDS, file No. 01-076-1393) ${ }^{31}$.

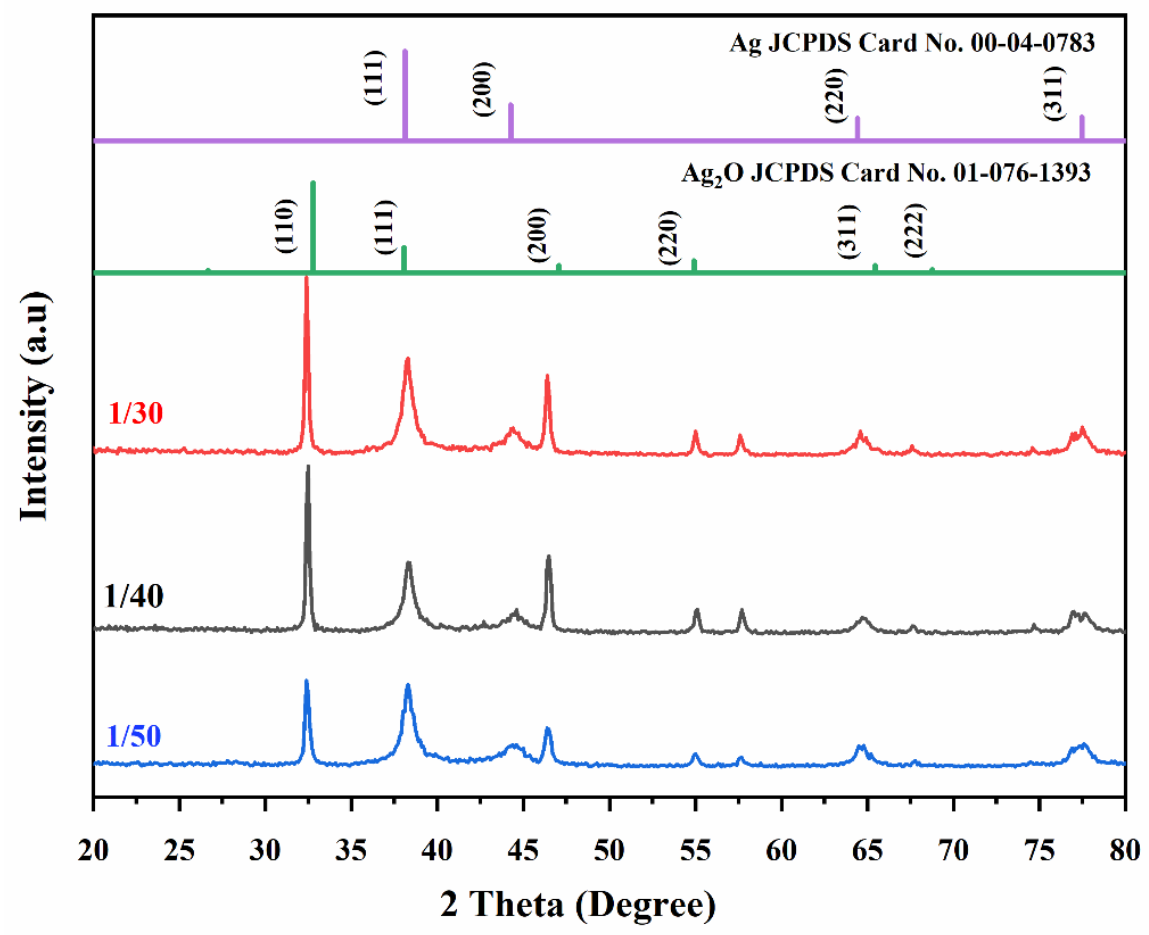

Figure 6. XRD patterns of $\mathrm{Ag} / \mathrm{Ag}_{2} \mathrm{O}$ at different volume ratios.

The crystallite size of the synthesized nanoparticles was estimated selecting the peak of highest intensity situated at $2 \theta$ value of $38.16^{\circ}$ using the Scherrer formula Eq (3):

$$
D=\frac{k \lambda}{\beta \cos \theta}
$$

Where $\mathrm{D}$ is the crystalline size $(\mathrm{nm}), \beta$ is the full width at half maximum of the diffraction peak (FWHM) of the most intense diffraction peak, $\lambda$ the X-ray wavelength $(1.5406 \AA)$ and $\theta$ is the Bragg angle of diffraction ${ }^{32}$.

The effect of the different volume ratios on crystallite size of $\mathrm{Ag} / \mathrm{Ag}_{2} \mathrm{O}$ are shown in Table 2 . 
Table 2. The effect of volume ratio on the crystallite size of $\mathrm{Ag} / \mathrm{Ag}_{2} \mathrm{ONPs}$.

\begin{tabular}{cc}
\hline Volume ratio & $\begin{array}{c}\mathrm{Ag} / \mathrm{Ag}_{2} \mathrm{ONPs} \text { Crystallite } \\
\text { size }(\mathrm{nm})\end{array}$ \\
\hline $1 / 30$ & $39.40 \pm 1.45$ \\
$1 / 40$ & $37.71 \pm 0.61$ \\
$1 / 50$ & $28.66 \pm 1.12$ \\
\hline
\end{tabular}

Table 2 shows that the crystallite size is affected by volume ratio. Noteworthy that increasing the volume ratio from $1 / 30$ to $1 / 40$ hasn't affected the $\mathrm{Ag} / \mathrm{Ag}_{2} \mathrm{O}$ NPs crystallite size significantly. In the other hand increasing the volume ratio from 1/40 to 1/50 has decreased the crystallite size of $\mathrm{Ag} / \mathrm{Ag}_{2} \mathrm{O}$ significantly from $37.71 \mathrm{~nm}$ to $28.66 \mathrm{~nm}$.

The decrease in crystallite size by increasing the amount of surfactant (plant extract) ratio has been also reported by many previous studies ${ }^{33,34}$.

\subsubsection{Scanning Electron Microscopy (SEM)}

SEM was used to study the formation of silver/silver oxide NP and its morphological size. Figure 7(a-c) shows the SEM images of the synthesized silver/silver oxide. It was observed that almost of them are spherical in nature shaped. Note that for the mixture of $\mathrm{Ag}$ and $\mathrm{Ag}_{2} \mathrm{O}$ nanoparticles; in addition, these particles converge into clusters to form foam (Figure $7 \mathrm{a}$ and b). A similar phenomenon has been reported in previous studies. 

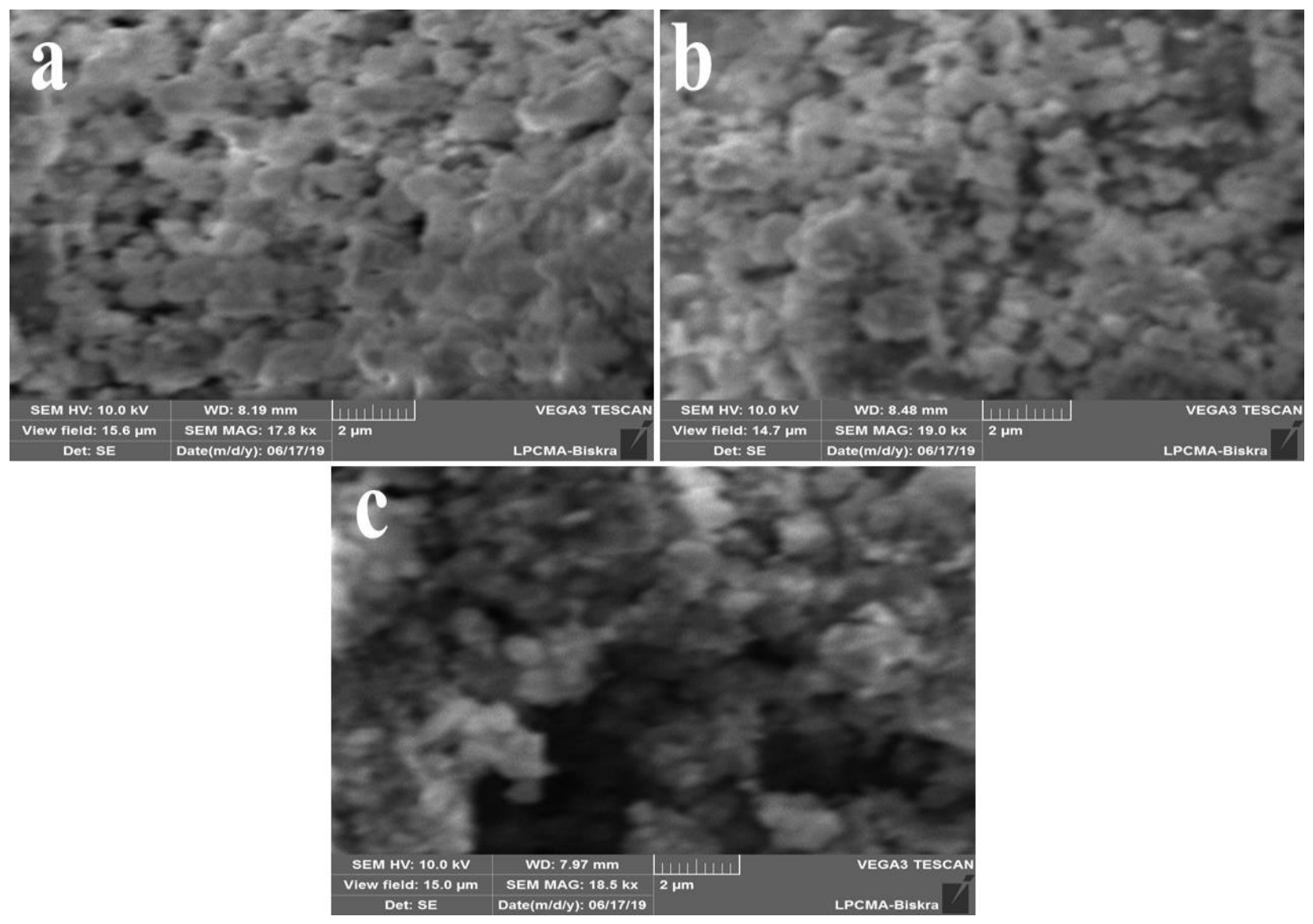

Figure 7 SEM images of green synthesized $\mathrm{Ag} / \mathrm{Ag}_{2} \mathrm{O}$ nanoparticles with different volume ratios: a) $1 / 30$, b) $1 / 40$, c) $1 / 50$

\subsection{Catalytic Activity for Dye Degradation}

\subsubsection{Catalytic activity towards $C R$ dye degradation}

Congo red consists of two phenyl ring bonded to two naphthalene terminal flats containing amino and sulfonic groups. Congo red is a toxic and carcinogenic metabolite dye used in industries such as the textile, paper, and rubber industries and causes bladder cancer in humans. Therefore, its reduction is an important issue due to its high environmental toxicity. The catalytic degradation of $\mathrm{CR}$ was monitored by biosynthetic silver nanoparticles under various experimental conditions. The Congo red aqueous solution shows two peaks at $340 \mathrm{~nm}$ and $490 \mathrm{~nm}$ in the UV-vis region, which binds to the azo $\left(-\mathrm{N}=\mathrm{N}_{-}\right.$) bond. During the $\mathrm{CR}$ reduction process, azo bonds in the dye molecule decompose and produce various aromatic amine products (sodium 4-amino-1naphthalene sulfonate and 1,1'-Biphenyl ). The $\mathrm{CR}$ dye molecules cannot be reduced in the aqueous medium in the presence of sodium borohydride $\left(\mathrm{NaBH}_{4}\right)$ as the reducing agent because this reaction is thermodynamically achievable but is not kinetically possible. Therefore, the use of silver / silver 
oxide nanoparticles as nanocatalysts provides the support and pathway via the transfer of electrons between the receiver $(\mathrm{CR})$ and the donor (borohydride ion $\left.\left(\mathrm{BH}_{4}^{-1}\right)\right)$. In addition, the silver nanoparticles provide a suitable surface for binding $\mathrm{CR}$ particles and borohydride ions $\left(\mathrm{BH}_{4}{ }^{-1}\right)$ to interact with each other to form decomposition products. These nano stimuli make the CR dye degradation process kinetically feasible, and reduction is complete in a very short period. A plausible decomposition mechanism for CR on the surface of bio-silver/ silver oxide nanoparticles is presented in Figure $8{ }^{35}$.

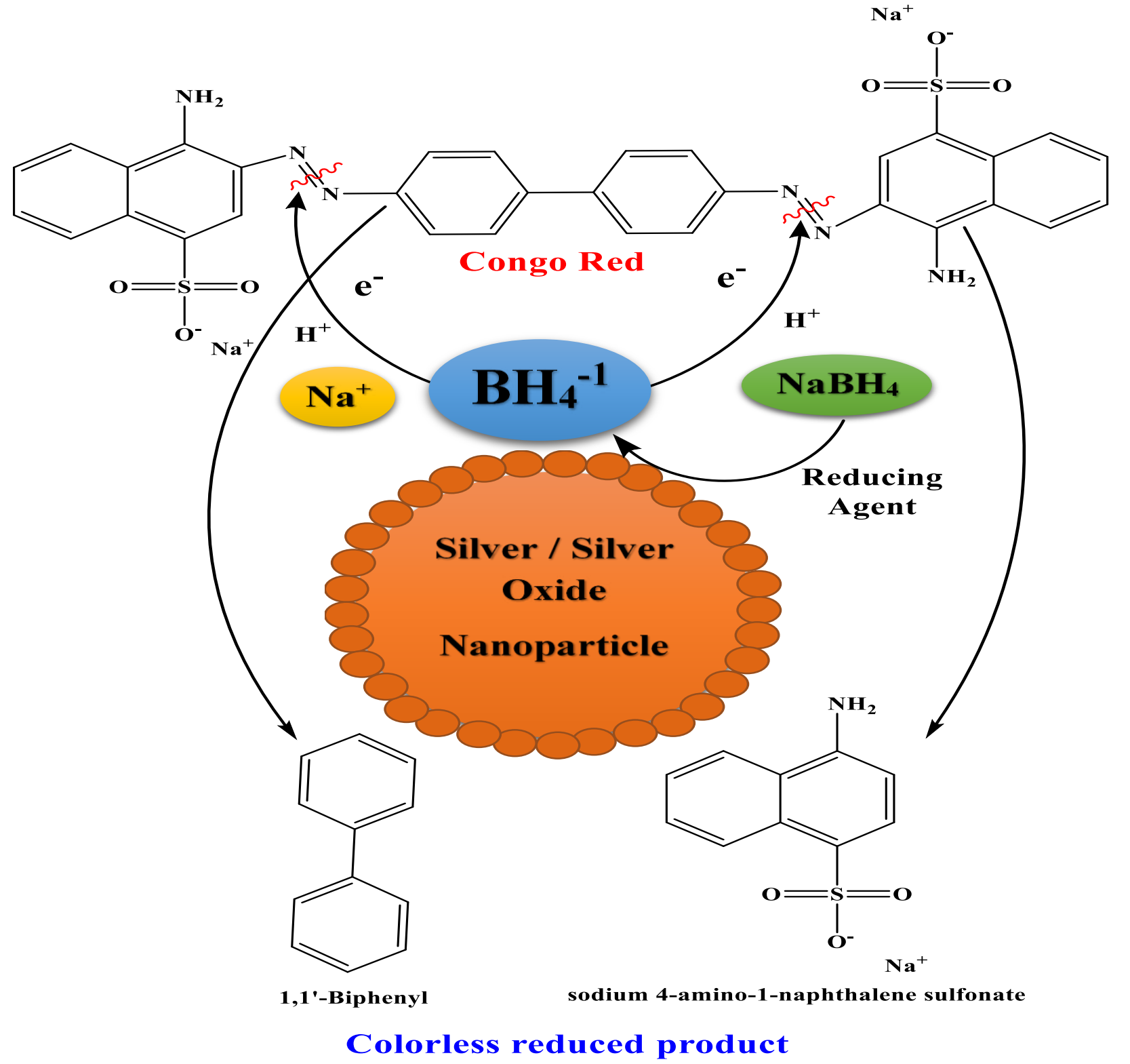

Figure 8 The Proposed mechanism for the silver/silver oxide nanoparticle-catalyzed reduction of $\mathrm{CR}$ using $\mathrm{NaBH}_{4}{ }^{35}$. 
Upon application of optimal experimental conditions, achieve an $80 \%$ degradation rate within 60 minutes was observed Figure 9 and Figure 10. The degradation efficiency is calculated by the following formula:

$$
\text { Degradation ratio (\%) }=\frac{C_{0}-C_{t}}{C_{t}} \times 100
$$

Where $C_{0}$ is the initial concentration of $\mathrm{CR}$ and $C_{t}$ is the immediate concentration in the sample.

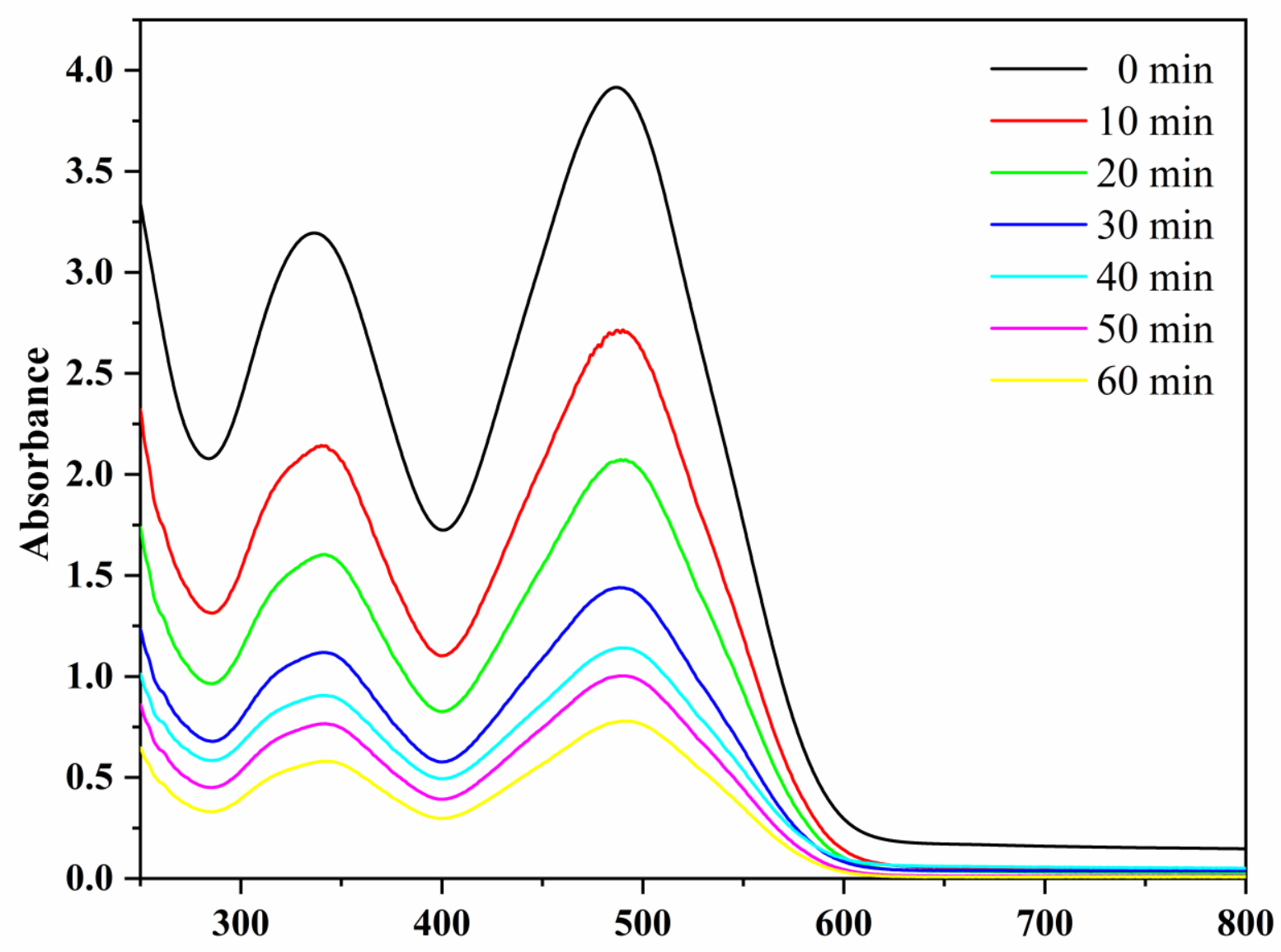

Figure $9 U V$-vis spectra versus congo red dye under optimal reaction conditions. 


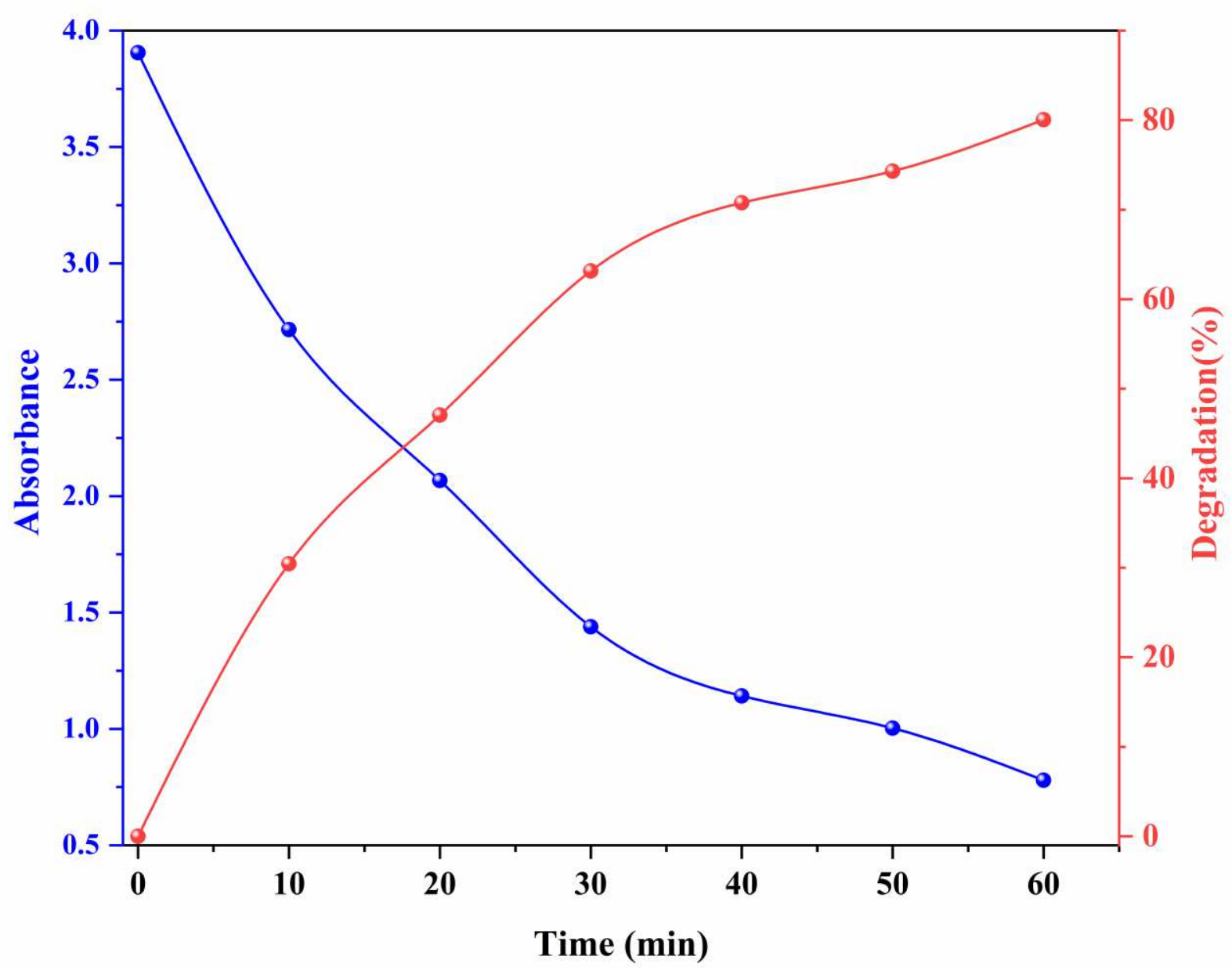

Figure 10 The graph of the decrease in absorbance and height percent of Congo red dye degradation versus time.

In order to determine the dye degradation kinetics of $C R$, the relationship between $\ln \left(\mathrm{C}_{0} / \mathrm{C}_{\mathrm{t}}\right)$ and irradiation time was plotted (as shown in Figure 11). It is found that under the catalysis of the silver/silver oxide nanocatalyst, the degradation reaction of CR basically obeys the first-order reaction kinetics ${ }^{35}$. Figure 11 shows a graph of $\ln \left(\mathrm{C}_{0} / \mathrm{C}_{\mathrm{t}}\right)$ versus time, which helps to understand the catalytic performance of biosynthetic silver nanoparticles. By plotting the relationship between $\ln \left(\mathrm{C}_{0} / \mathrm{C}_{\mathrm{t}}\right)$ and time, the kinetic parameters of $\mathrm{CR}$ dye degradation under optimal reaction conditions were studied. As shown in Figure 10, a linear relationship between $\ln \left(\mathrm{C}_{0} / \mathrm{C}_{\mathrm{t}}\right)$ and time is observed, and the reaction follows a pseudo-first order kinetics. Therefore, the reaction rate is determined by $\ln \left(C_{0} / C_{t}\right)=K_{a p p} . t$, where $\mathrm{C}_{0}$ and $\mathrm{C}_{\mathrm{t}}$ are the concentration or absorbance of $\mathrm{CR}$ dye before and after degradation, and $\mathrm{K}_{\mathrm{app}}$ is the apparent rate $\left(\mathrm{min}^{-1}\right)$. The value of the apparent rate constant $\left(\mathrm{k}_{\mathrm{app}}\right)$ is calculated from the slope of the straight line using the above formula $k_{a p p}=0.01151 \mathrm{~min}^{-1}{ }^{36}$. The 
results further prove that the silver/silver oxide nano-catalyst exhibits good photoreactivity, which confirms the corresponding degradation efficiency ${ }^{37}$.

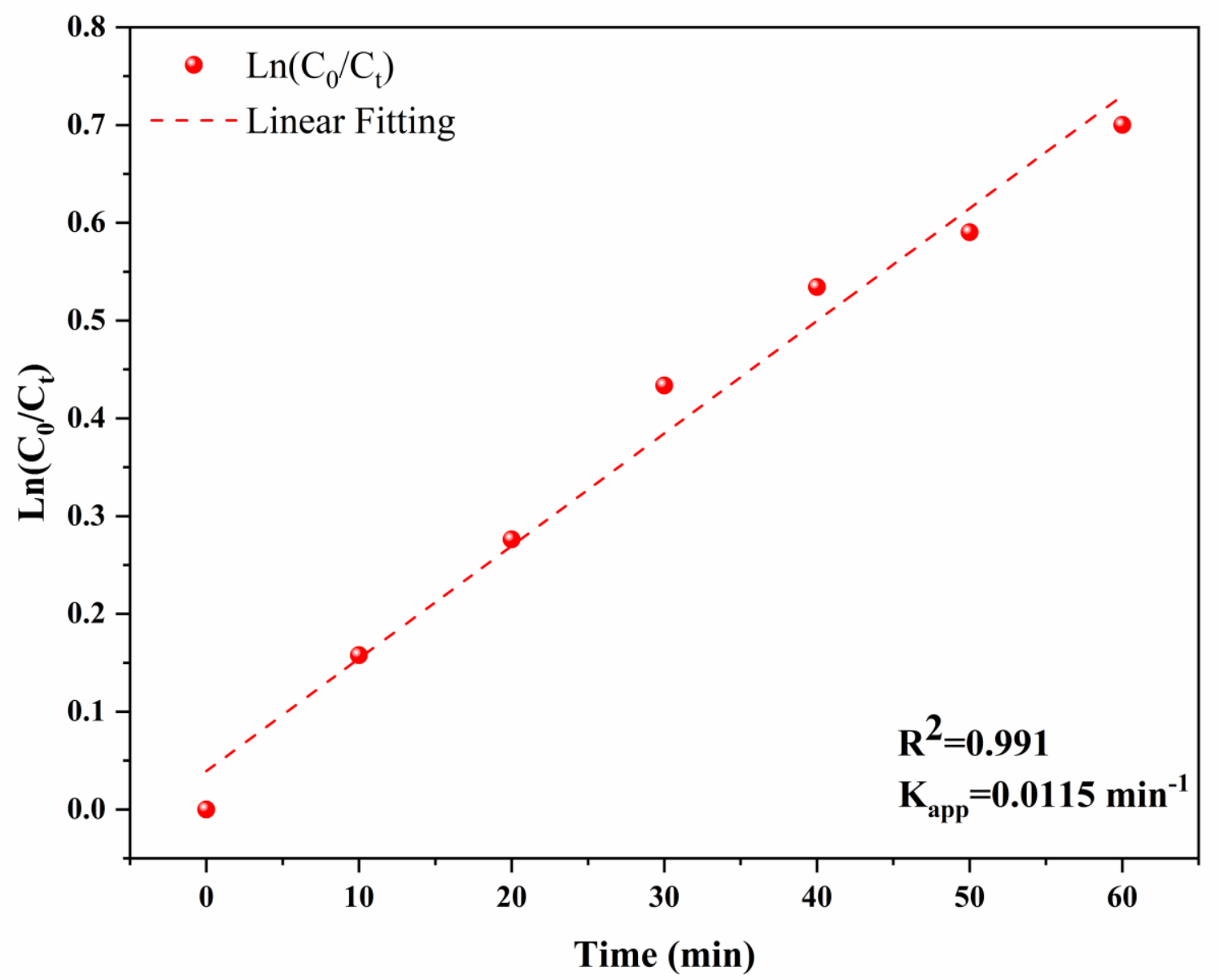

Figure 11 Plot of $\ln \left(C_{0} / C_{t}\right)$ versus time for the silver /silver oxide nanoparticle-catalysed degradation of Congo red.

\subsubsection{Catalytic Degradation of $M B$}

The catalytic hydrolysis of the dye in the presence of $\mathrm{NaBH}_{4}$ was examined, which is another typical reaction to confirm the catalytic activity of $\mathrm{Ag} / \mathrm{Ag}_{2} \mathrm{O}$ NPs and MB. The stimulation is monitored by UV-Vis spectroscopy. By adding $\mathrm{Ag} / \mathrm{Ag}_{2} \mathrm{O}$ NPs as compounds to the reaction mixture, the catalytic reduction of the dye takes place immediately. The strong blue color of the MB solution fades and becomes colorless after 8 minutes during the degradation process Figure 13. Calculate the degradation percentage (Figure 14) as a quantitative expression of degraded dyes. The presence of amide groups of $\mathrm{Ag} / \mathrm{Ag}_{2} \mathrm{O}$ NPs in the transfer of electrons from $\mathrm{BH}^{-}$anions to MB cations, which increases with increasing time, which was also similar to the previously 
reported micro $\mathrm{Ag} / \mathrm{Ag}_{2} \mathrm{O}$ NPs ${ }^{38-45}$. The initial absorption peak at $663 \mathrm{~nm}$ gradually decreased over time, confirming the catalytic activity of the composite $\mathrm{Ag} / \mathrm{Ag}_{2} \mathrm{O}$ NPs (Figure 14). Figure 12 schematically illustrates the mechanism of the catalytic degradation process.

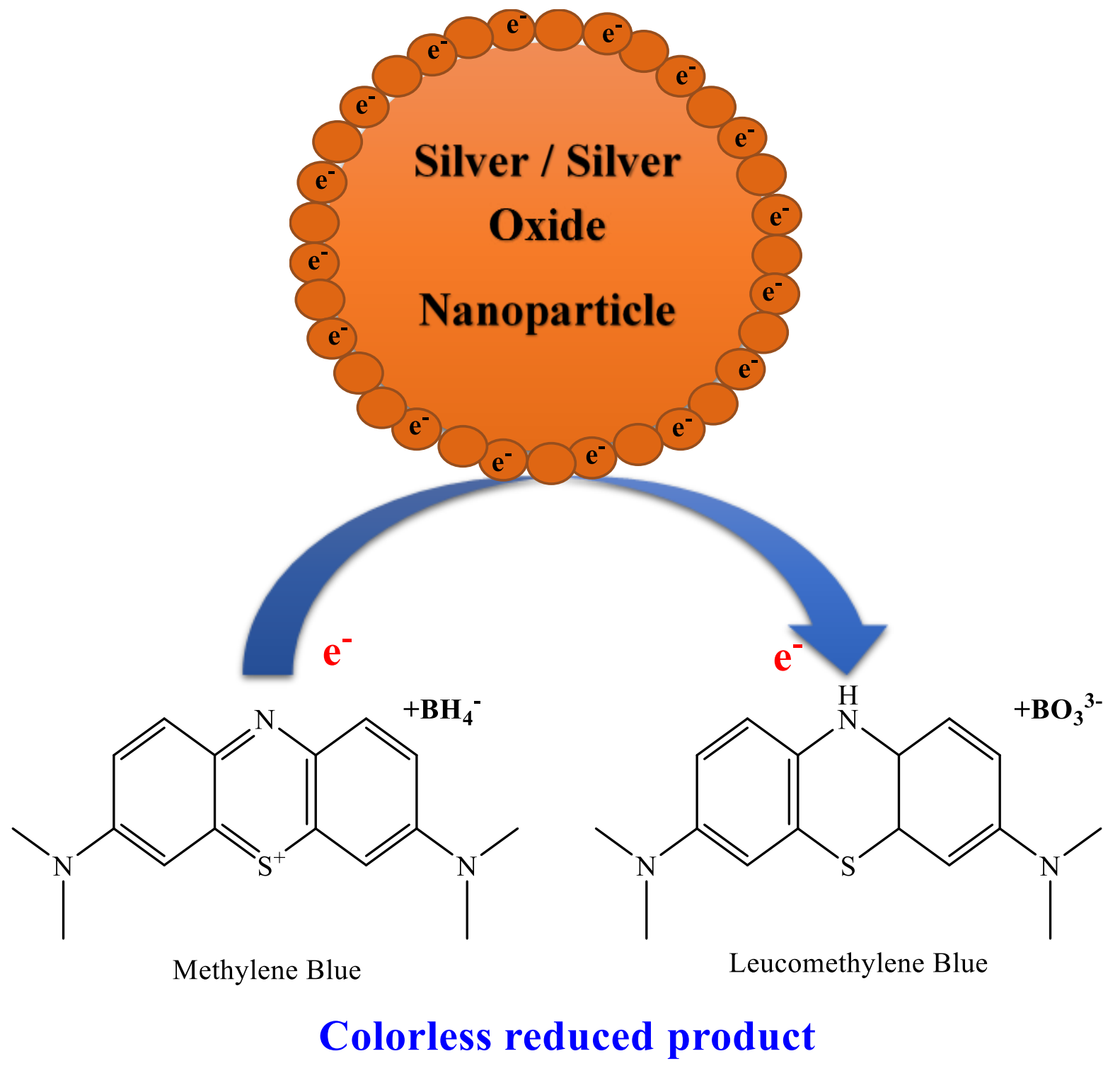

Figure 12 Schematic illustration of the catalytic degradation of MB process by $\mathrm{Ag} / \mathrm{Ag}_{2} \mathrm{O} \mathrm{NPs}$ 


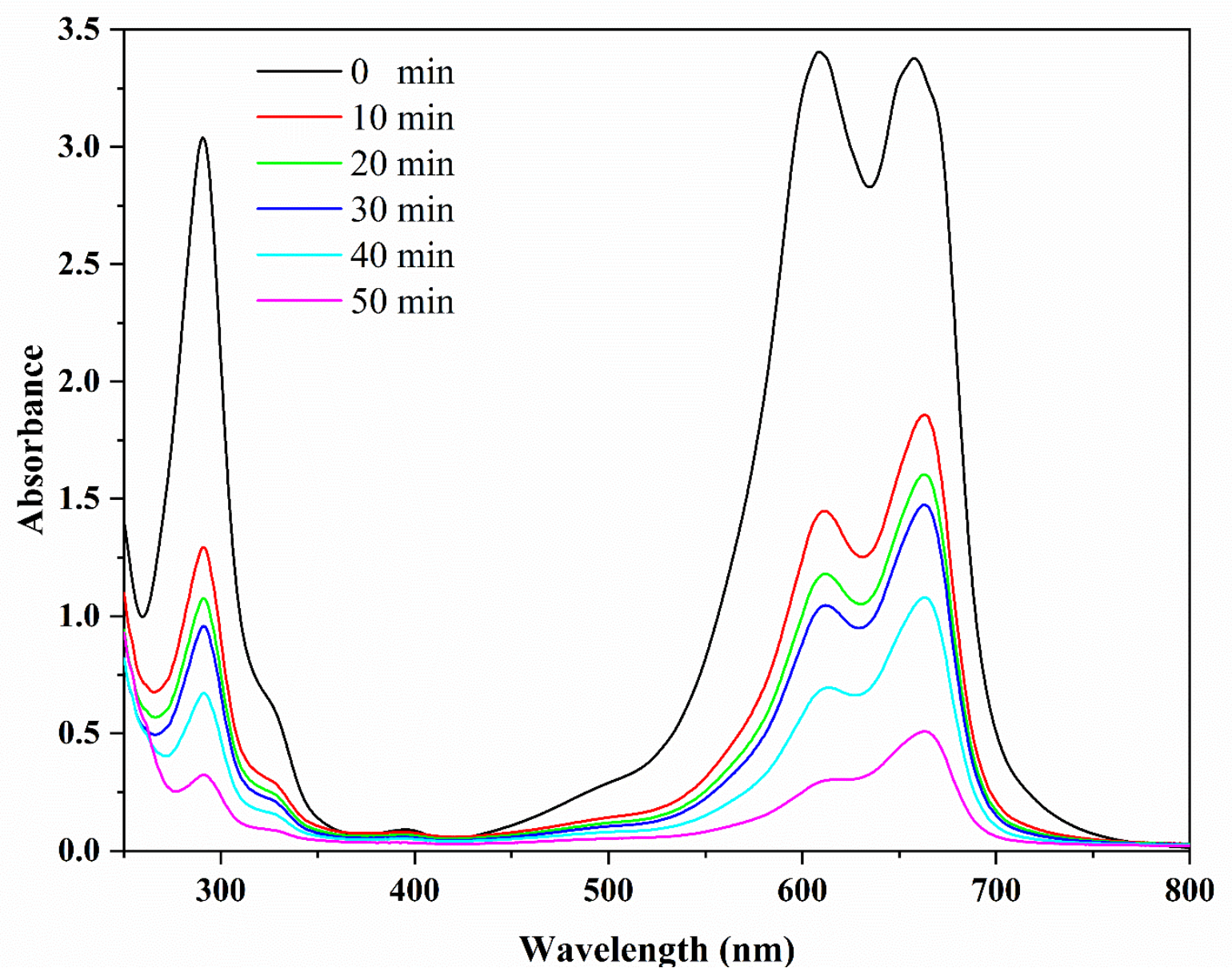

Figure $13 \mathrm{UV}$-vis spectra for the reduction of $\mathrm{MB}$ using $\mathrm{Ag} / \mathrm{Ag}_{2} \mathrm{O} \mathrm{NPs}$ 


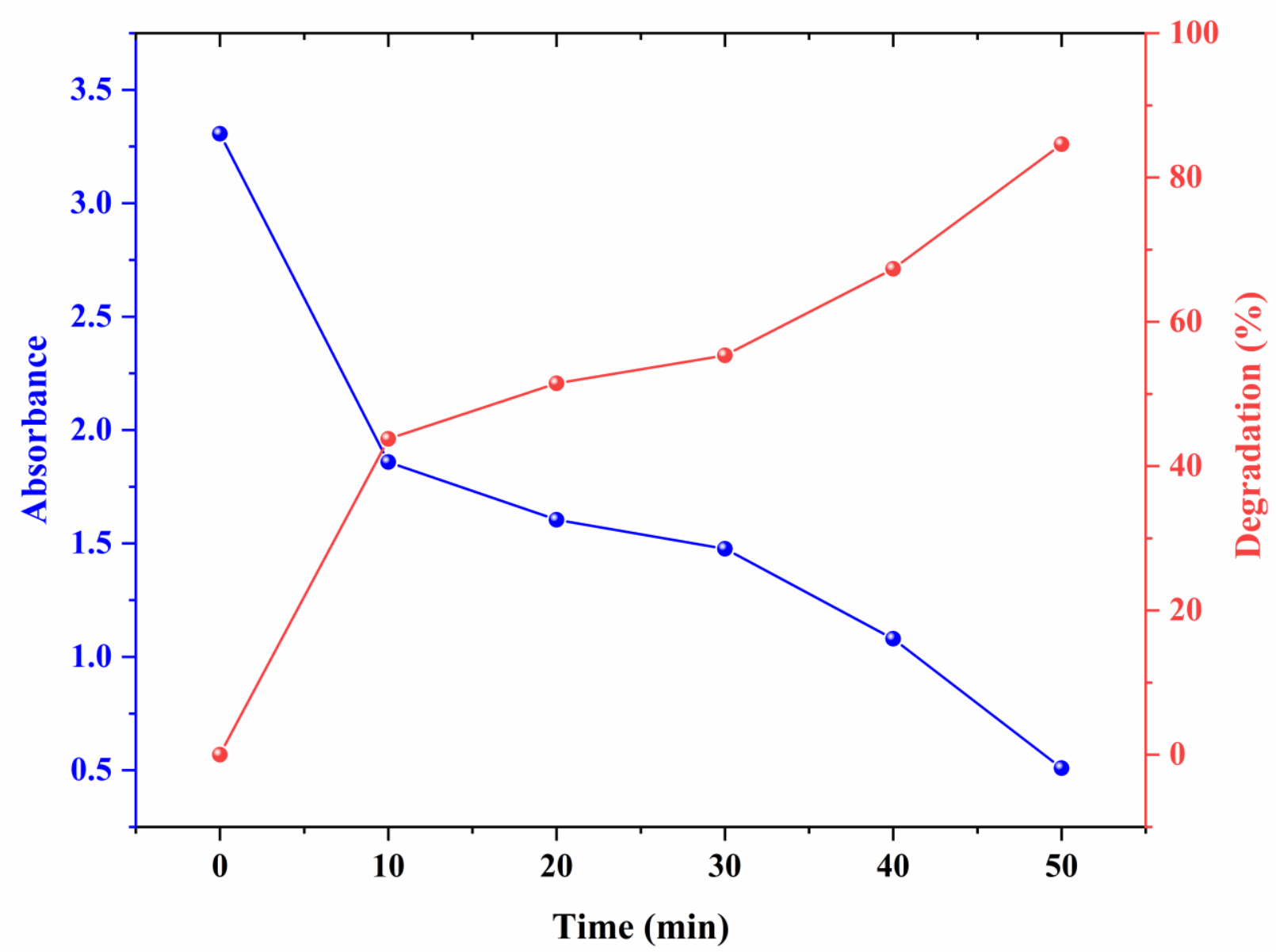

Figure 14 Plot of In (Ct/CO) versus time for the silver /silver oxide nanoparticle-catalysed degradation of Methylene blue.

The addition of biosynthetic silver nanoparticles improves the reduction process (the dye degrades up to $84.60 \%$ in 50 minutes). Analysis of the degradation reaction kinetics data showed pseudo first-order reaction kinetics. The reaction rate is determined by $\ln \left(\mathrm{C}_{\mathrm{t}} / \mathrm{C}_{0}\right)=-\mathrm{K}_{\mathrm{app}} . \mathrm{t}$, where $\mathrm{C}_{0}$ and $\mathrm{C}_{\mathrm{t}}$ are the concentration or absorbance of MB dye before and after degradation. The slope of the curve determines the $k_{a p p}$ (min-1) value. The linear graph of $\ln \left(C_{t} / C_{0}\right)$ versus time (Figure 15) supports the kinetic theory, where the $\mathrm{k}$ value is $0.137 \mathrm{~min}-1^{46}$. 


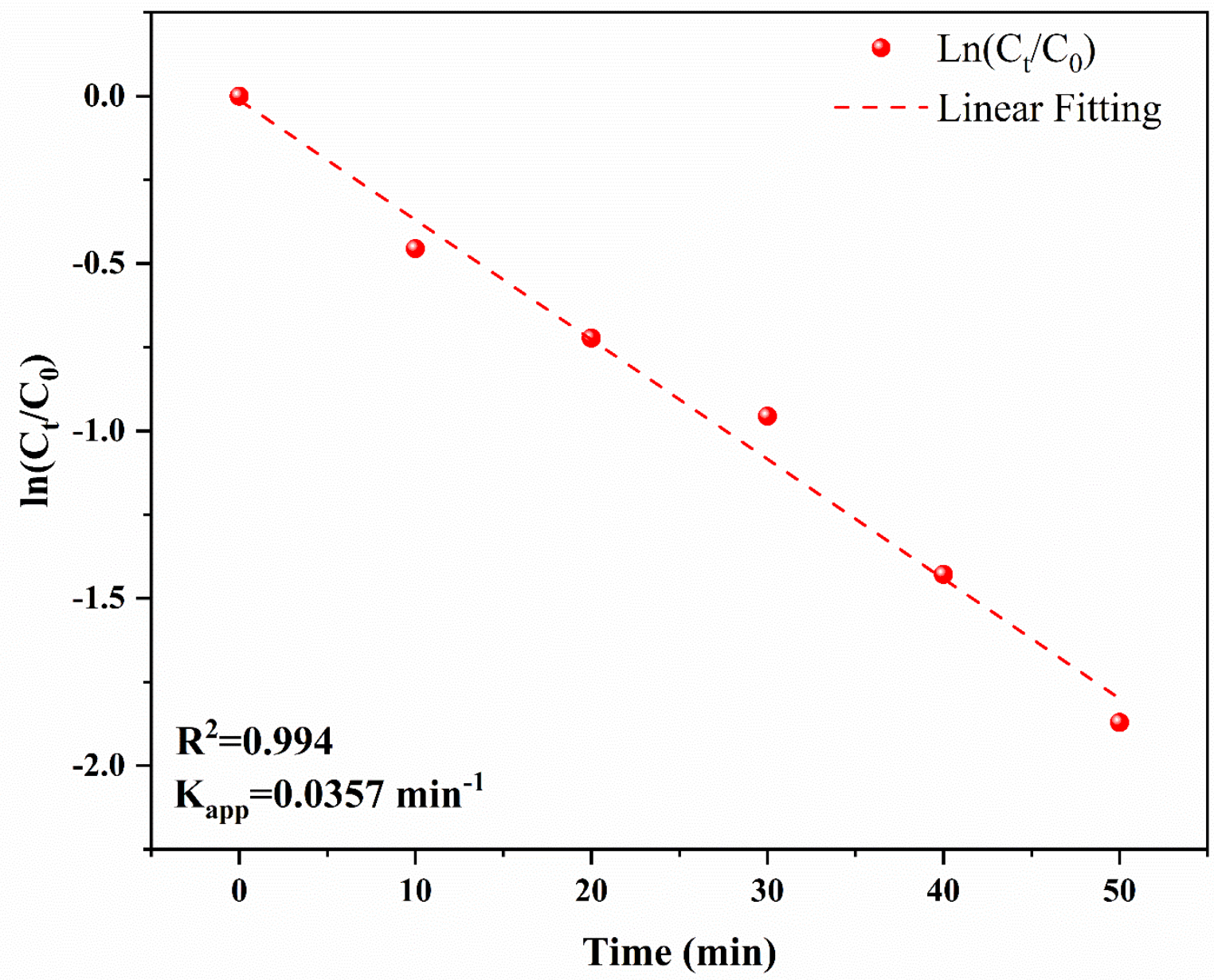

Figure 15 Plot of $\ln (\mathrm{Ct} / \mathrm{CO})$ against reaction time for the catalytic reduction of $\mathrm{MB}$ with $\mathrm{Ag} / \mathrm{Ag}_{2} \mathrm{O}$ $N P S$

\section{Conclusion}

In this study, the green synthesis of silver/silver oxide nanoparticles was successfully performed using Phoenix Dactylifera $L$ aqueous leaf extract. The process is relatively easy, fast, cheap, environmentally friendly, and does not require any organic solvents or other toxic reagents. Therefore, this synthesis method is more beneficial than conventional methods for the synthesis of $\mathrm{Ag} / \mathrm{Ag}_{2} \mathrm{O}$ NP. The shape of the prepared $\mathrm{Ag} / \mathrm{Ag}_{2} \mathrm{O}$ NPs is close to spherical, the crystal in nature, and the average diameter is $28.66-39.40 \mathrm{~nm}$. In addition, this study shows that the prepared $\mathrm{Ag} / \mathrm{Ag}_{2} \mathrm{O}$ NPs have good catalytic activity for dye degradation of $\mathrm{MB}$ and $\mathrm{CR}$ stains under environmental conditions. The compound $\mathrm{Ag} / \mathrm{Ag}_{2} \mathrm{O}$ NP is proved to be useful in the treatment of wastewater (dye degradation) in medicines, cosmetics, paints, plastics, and textiles. 


\section{CONSENT FOR PUBLICATION}

Not applicable.

\section{FUNDING}

None.

\section{CONFLICT OF INTERES}

The authors declare no conflict of interest, financial or otherwise.

\section{References}

1. Khare, S., Williams, K. \& Gokulan, K. Nanotechnology. in (eds. Batt, C. A. \& Tortorello, M. L. B. T.-E. of F. M. (Second E.) 893-900 (Academic Press, 2014). doi:https://doi.org/10.1016/B978-012-384730-0.00406-7.

2. Lyddy, R. Chapter 36 - Nanotechnology. in (eds. Wexler, P., Gilbert, S. G., Hakkinen, P. J. \& Mohapatra, A. B. T.-I. R. in T. (Fourth E.) 321-328 (Academic Press, 2009). doi:https://doi.org/10.1016/B978-0-12-373593-5.00036-7.

3. Johnson, S. Nanotechnology. in (ed. Chadwick, R. B. T.-E. of A. E. (Second E.) 182-185 (Academic Press, 2012). doi:https://doi.org/10.1016/B978-0-12-373932-2.00044-2.

4. Sithara, R., Selvakumar, P., Arun, C., Anandan, S. \& Sivashanmugam, P. Economical synthesis of silver nanoparticles using leaf extract of Acalypha hispida and its application in the detection of Mn(II) ions. J. Adv. Res. 8, 561-568 (2017).

5. Bouafia, A. \& Laouini, S. E. Green synthesis of iron oxide nanoparticles by aqueous leaves extract of Mentha Pulegium L.: Effect of ferric chloride concentration on the type of product. Mater. Lett. 265, (2020).

6. Bouafia, A., Laouini, S. E. S. E., Khelef, A., Tedjani, M. L. M. L. \& Guemari, F. Effect of Ferric Chloride Concentration on the Type of Magnetite (Fe3O4) Nanoparticles Biosynthesized by Aqueous Leaves Extract of Artemisia and Assessment of Their Antioxidant Activities. J. Clust. Sci. (2020) doi:10.1007/s10876-020-01868-7.

7. Laid, T. M., Abdelhamid, K., Eddine, L. S. \& Abderrhmane, B. Optimizing the biosynthesis parameters of iron oxide nanoparticles using central composite design. J. Mol. Struct. 129497 (2020) 
doi:10.1016/j.molstruc.2020.129497.

8. Abdullah, J. A. A. et al. Green synthesis and characterization of iron oxide nanoparticles by pheonix dactylifera leaf extract and evaluation of their antioxidant activity. Sustain. Chem. Pharm. 17, $100280(2020)$.

9. Bouafia, A., Laouini, S. E. \& Ouahrani, M. R. A Review on Green Synthesis of CuO Nanoparticles using Plant Extract and Evaluation of Antimicrobial Activity. Asian J. Res. Chem. 13, 65 (2020).

10. Bouafia, A. \& Laouini, S. E. Plant-Mediated Synthesis of Iron Oxide Nanoparticles and Evaluation of the Antimicrobial Activity: A Review. Mini. Rev. Org. Chem. 17, 1-11 (2020).

11. Menon, S., S., R. \& S., V. K. A review on biogenic synthesis of gold nanoparticles, characterization, and its applications. Resour. Technol. 3, 516-527 (2017).

12. Zhang, X. et al. Biogenic synthesis of gold nanoparticles by yeast Magnusiomyces ingens LH-F1 for catalytic reduction of nitrophenols. Colloids Surfaces A Physicochem. Eng. Asp. 497, 280-285 (2016).

13. Du, L., Jiang, H., Liu, X. \& Wang, E. Biosynthesis of gold nanoparticles assisted by Escherichia coli DH5 $\alpha$ and its application on direct electrochemistry of hemoglobin. Electrochem. commun. 9, 11651170 (2007).

14. Dumur, F. et al. Controlled spontaneous generation of gold nanoparticles assisted by dual reducing and capping agents. Gold Bull. 44, 119-137 (2011).

15. Sarkar, J., Ray, S., Chattopadhyay, D., Laskar, A. \& Acharya, K. Mycogenesis of gold nanoparticles using a phytopathogen Alternaria alternata. Bioprocess Biosyst. Eng. 35, 637-643 (2012).

16. Ghosh, P. \& Roychoudhury, A. Nutrition and antioxidant profiling in the unpolished and polished grains of eleven indigenous aromatic rice cultivars. 3 Biotech 10, 548 (2020).

17. Bouafia, A. \& Laouini, S. E. Green synthesis of iron oxide nanoparticles by aqueous leaves extract of Mentha Pulegium L.: Effect of ferric chloride concentration on the type of product. Mater. Lett. 265, 127364 (2020).

18. Boulenouar, N., Marouf, A. \& Cheriti, A. Antifungal activity and phytochemical screening of extracts from Phoenix dactylifera L. cultivars. Nat. Prod. Res. 25, 1999-2002 (2011).

19. Karunakaran, G. et al. Allamanda cathartica flower's aqueous extract-mediated green synthesis of silver nanoparticles with excellent antioxidant and antibacterial potential for biomedical application. 
MRS Commun. 6, 41-46 (2016).

20. He, R., Qian, X., Yin, J. \& Zhu, Z. Preparation of polychrome silver nanoparticles in different solvents. J. Mater. Chem. 12, 3783-3786 (2002).

21. Singh, R. et al. Synthesis, optimization, and characterization of silver nanoparticles from Acinetobacter calcoaceticus and their enhanced antibacterial activity when combined with antibiotics. Int. J. Nanomedicine 8, 4277 (2013).

22. Strehlow, W. H. \& Cook, E. L. Compilation of Energy Band Gaps in Elemental and Binary Compound Semiconductors and Insulators. J. Phys. Chem. Ref. Data 2, 163-200 (1973).

23. Mallick, P. \& Dash, B. N. X-ray diffraction and UV-visible characterizations of $\alpha-\mathrm{Fe} 2 \mathrm{O} 3$ nanoparticles annealed at different temperature. J. Nanosci. Nanotechnol 3, 130-134 (2013).

24. Jayaprakash, P., Mohamed, M. P. \& Caroline, M. L. Growth, spectral and optical characterization of a novel nonlinear optical organic material: d-Alanine dl-Mandelic acid single crystal. J. Mol. Struct. 1134, 67-77 (2017).

25. Martienssen, W. Über die excitonenbanden der alkalihalogenidkristalle. J. Phys. Chem. Solids 2, 257-267 (1957).

26. Auti, A. M., Narwade, N. P., Deshpande, N. M. \& Dhotre, D. P. Microbiome and imputed metagenome study of crude and refined petroleum-oil-contaminated soils: Potential for hydrocarbon degradation and plant-growth promotion. J. Biosci. 44, 114 (2019).

27. Raj, A. et al. Green synthesis and charcterization of silver nanoparticles from leafs extracts of rosa indica and its antibacterial activity against human pathogen bacteria. Orient. J. Chem. 34, 326-335 (2018).

28. Arif, D., Niazi, M. B. K., Ul-Haq, N., Anwar, M. N. \& Hashmi, E. Preparation of antibacterial cotton fabric using chitosan-silver nanoparticles. Fibers Polym. 16, 1519-1526 (2015).

29. Priyadharshini, R. I., Prasannaraj, G., Geetha, N. \& Venkatachalam, P. Microwave-Mediated Extracellular Synthesis of Metallic Silver and Zinc Oxide Nanoparticles Using Macro-Algae (Gracilaria edulis) Extracts and Its Anticancer Activity Against Human PC3 Cell Lines. Appl. Biochem. Biotechnol. 174, 2777-2790 (2014).

30. Meng, Y. A sustainable approach to fabricating ag nanoparticles/PVA hybrid nanofiber and its catalytic activity. Nanomaterials 5, 1124-1135 (2015). 
31. Rajabi, A. et al. Development and antibacterial application of nanocomposites: Effects of molar ratio on $\mathrm{Ag} 2 \mathrm{O}-\mathrm{CuO}$ nanocomposite synthesised via the microwave-assisted route. Ceram. Int. 44, 2159121598 (2018).

32. Langford, J. I. X-ray diffraction procedures for polycrystalline and amorphous materials by H. P. Klug and L. E. Alexander. J. Appl. Crystallogr. 8, 573-574 (1975).

33. Moya, C., Batlle, X. \& Labarta, A. The effect of oleic acid on the synthesis of Fe3-xO4 nanoparticles over a wide size range. Phys. Chem. Chem. Phys. 17, 27373-27379 (2015).

34. Sharifi Dehsari, H. et al. Effect of precursor concentration on size evolution of iron oxide nanoparticles. CrystEngComm 19, 6694-6702 (2017).

35. Royji Albeladi, S. S., Malik, M. A. \& Al-thabaiti, S. A. Facile biofabrication of silver nanoparticles using Salvia officinalis leaf extract and its catalytic activity towards Congo red dye degradation. $J$. Mater. Res. Technol. 9, 10031-10044 (2020).

36. Erdemoğlu, S. et al. Photocatalytic degradation of Congo Red by hydrothermally synthesized nanocrystalline $\mathrm{TiO} 2$ and identification of degradation products by LC-MS. J. Hazard. Mater. 155, 469-476 (2008).

37. Alkaykh, S., Mbarek, A. \& Ali-Shattle, E. E. Photocatalytic degradation of methylene blue dye in aqueous solution by $\mathrm{MnTiO}(3)$ nanoparticles under sunlight irradiation. Heliyon 6, e03663-e03663 (2020).

38. Nasrollahzadeh, M., Atarod, M., Jaleh, B. \& Gandomirouzbahani, M. In situ green synthesis of Ag nanoparticles on graphene oxide/TiO2 nanocomposite and their catalytic activity for the reduction of 4-nitrophenol, congo red and methylene blue. Ceram. Int. 42, 8587-8596 (2016).

39. Hemraj-Benny, T. et al. Microwave-assisted synthesis of single-walled carbon nanotube-supported ruthenium nanoparticles for the catalytic degradation of Congo red dye. Mater. Chem. Phys. 216, 72-81 (2018).

40. Jo, W.-K., Kumar, S., Isaacs, M. A., Lee, A. F. \& Karthikeyan, S. Cobalt promoted TiO2/GO for the photocatalytic degradation of oxytetracycline and Congo Red. Appl. Catal. B Environ. 201, 159-168 (2017).

41. Naseem, K., Farooqi, Z. H., Begum, R. \& Irfan, A. Removal of Congo red dye from aqueous medium by its catalytic reduction using sodium borohydride in the presence of various inorganic nanocatalysts: A review. J. Clean. Prod. 187, 296-307 (2018). 
42. Fowsiya, J., Madhumitha, G., Al-Dhabi, N. A. \& Arasu, M. V. Photocatalytic degradation of Congo red using Carissa edulis extract capped zinc oxide nanoparticles. J. Photochem. Photobiol. B Biol. 162, 395-401 (2016).

43. Raj, S., Singh, H., Trivedi, R. \& Soni, V. Biogenic synthesis of AgNPs employing Terminalia arjuna leaf extract and its efficacy towards catalytic degradation of organic dyes. Sci. Rep. 10, 9616 (2020).

44. Liu, J. et al. Ag-ZnO Submicrometer Rod Arrays for High-Efficiency Photocatalytic Degradation of Congo Red and Disinfection. ACS Sustain. Chem. Eng. 7, 11258-11266 (2019).

45. Nasrollahzadeh, M., Issaabadi, Z. \& Sajadi, S. M. Green synthesis of Cu/Al2O3 nanoparticles as efficient and recyclable catalyst for reduction of 2,4-dinitrophenylhydrazine, Methylene blue and Congo red. Compos. Part B Eng. 166, 112-119 (2019).

46. Fairuzi, A. A., Bonnia, N. N., Akhir, R. M., Abrani, M. A. \& Akil, H. M. Degradation of methylene blue using silver nanoparticles synthesized fromimperata cylindricaaqueous extract. IOP Conf. Ser. Earth Environ. Sci. 105, 12018 (2018). 
Figures

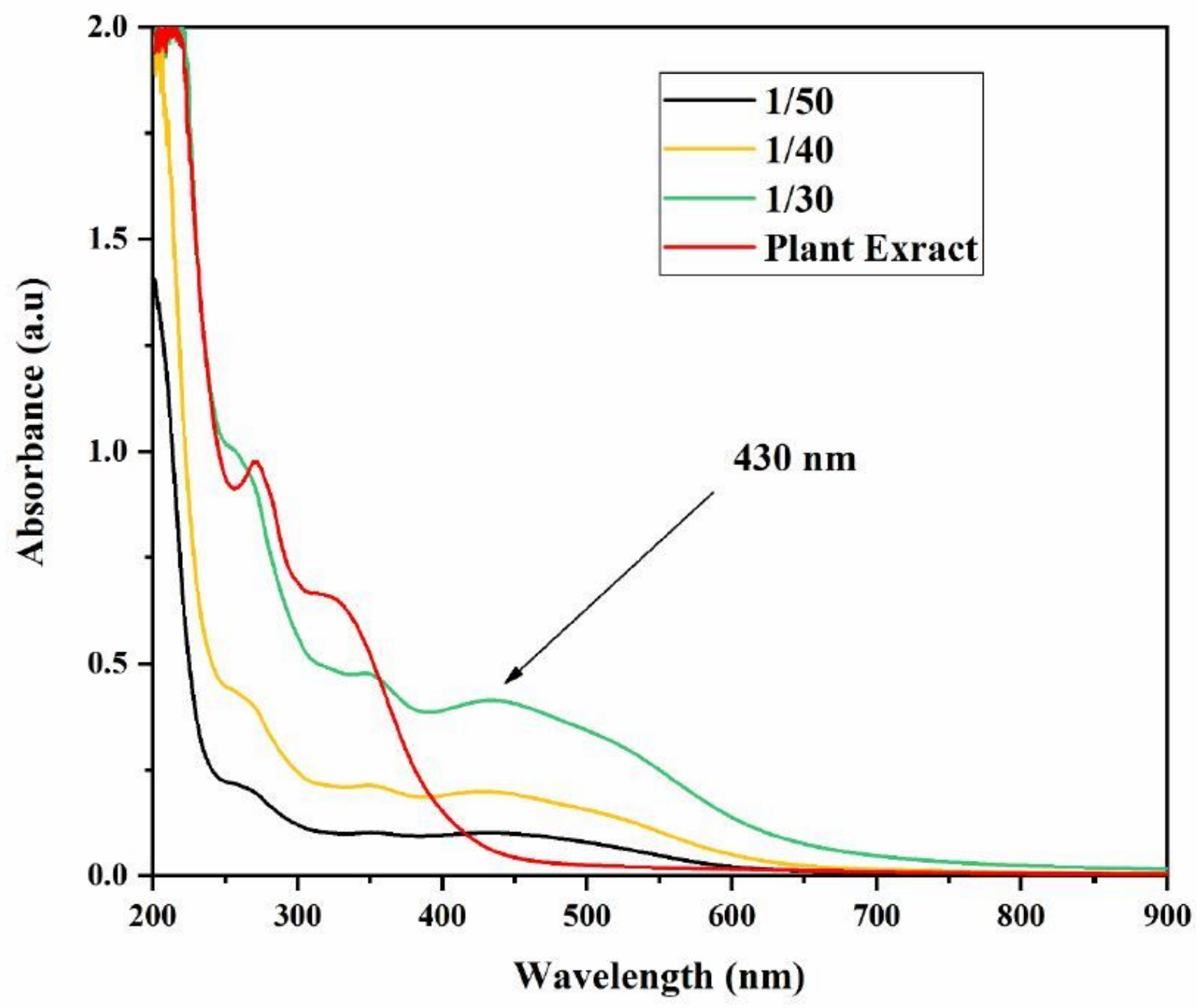

Figure 1

UV-visible Spectrum of Ag/Ag20 and plant Extract. 


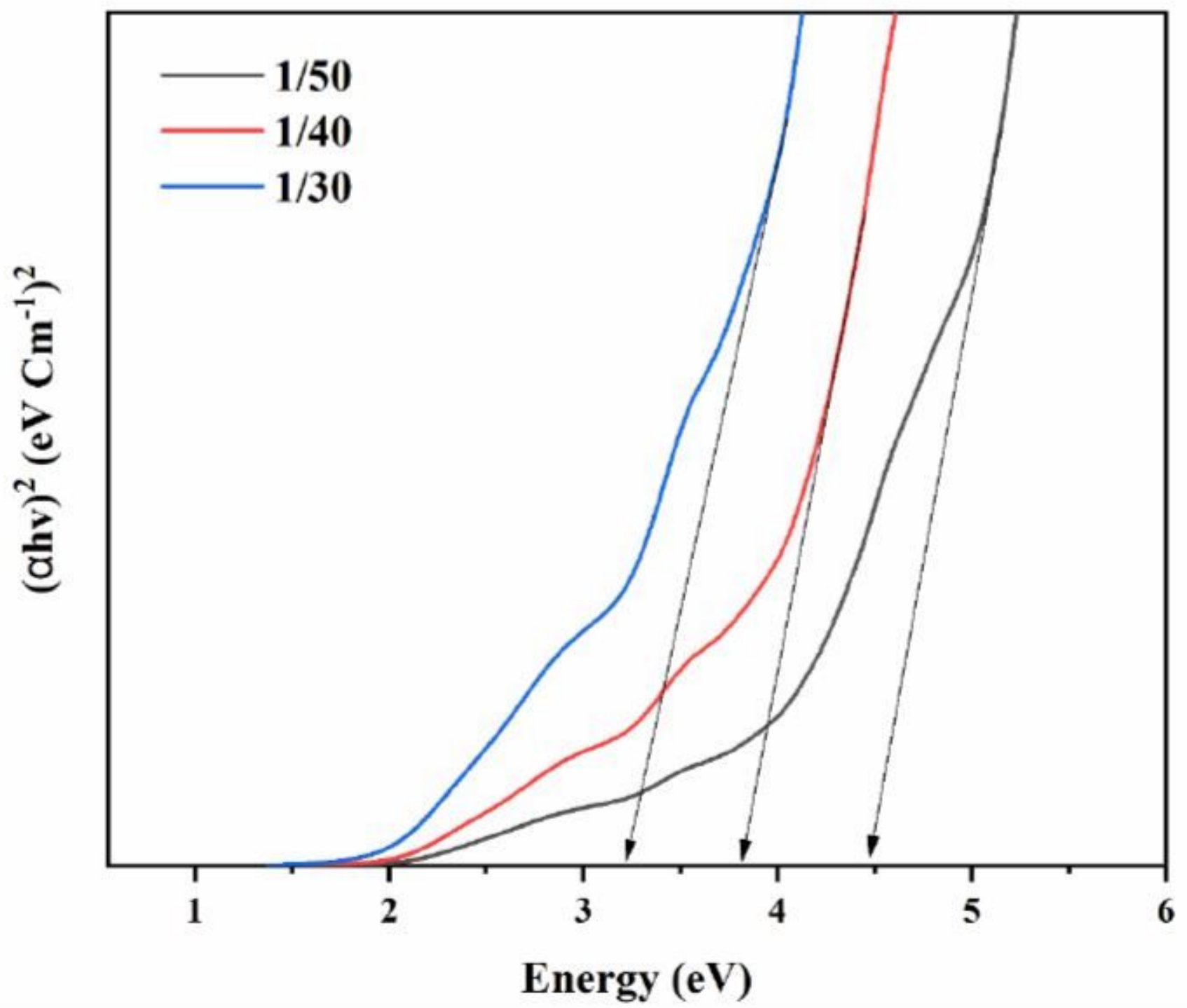

Figure 2

Determination of optical energy gap for direct transition using Tauc's method. 


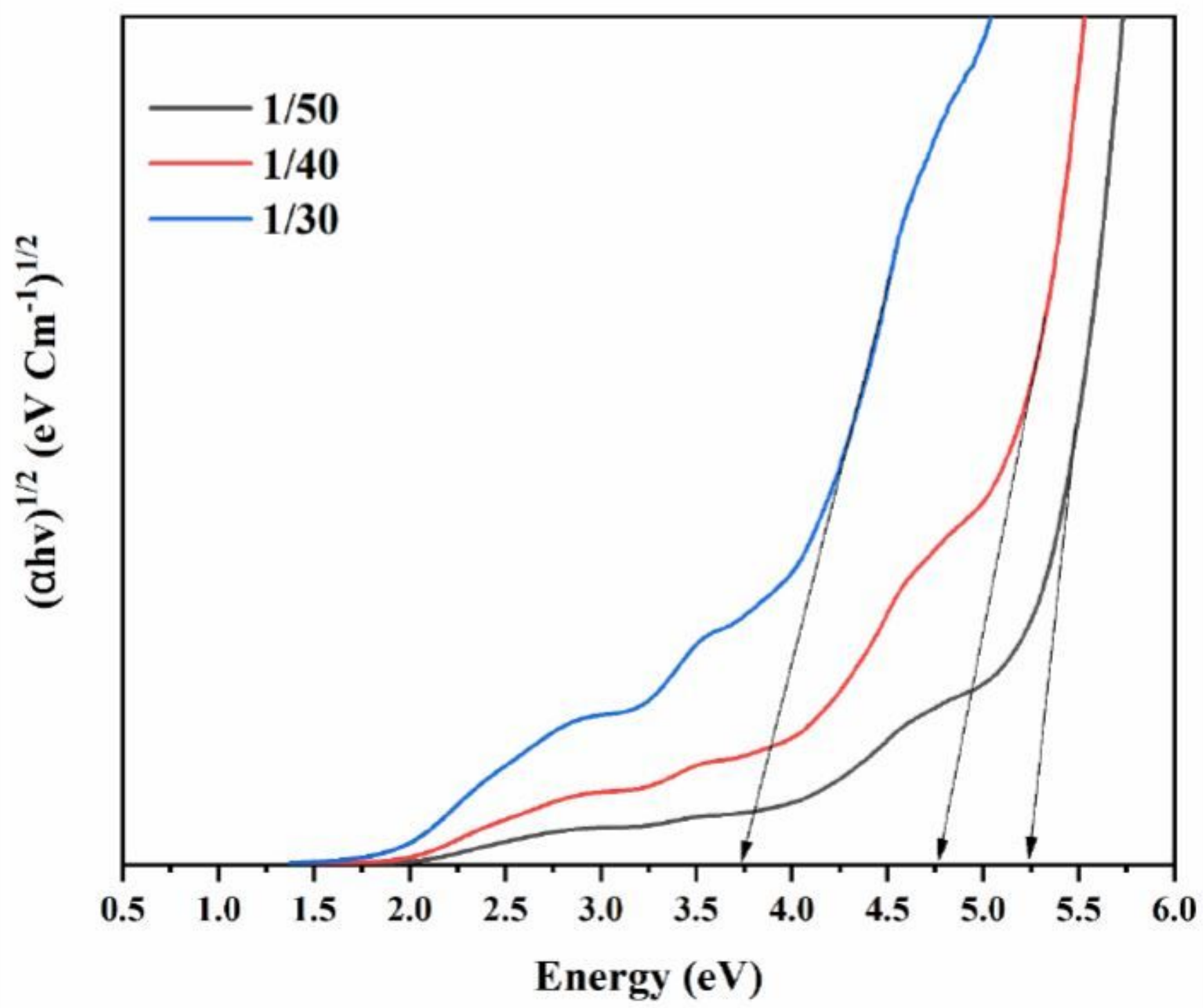

Figure 3

Determination of optical energy gap for indirect transition using Tauc's method. 


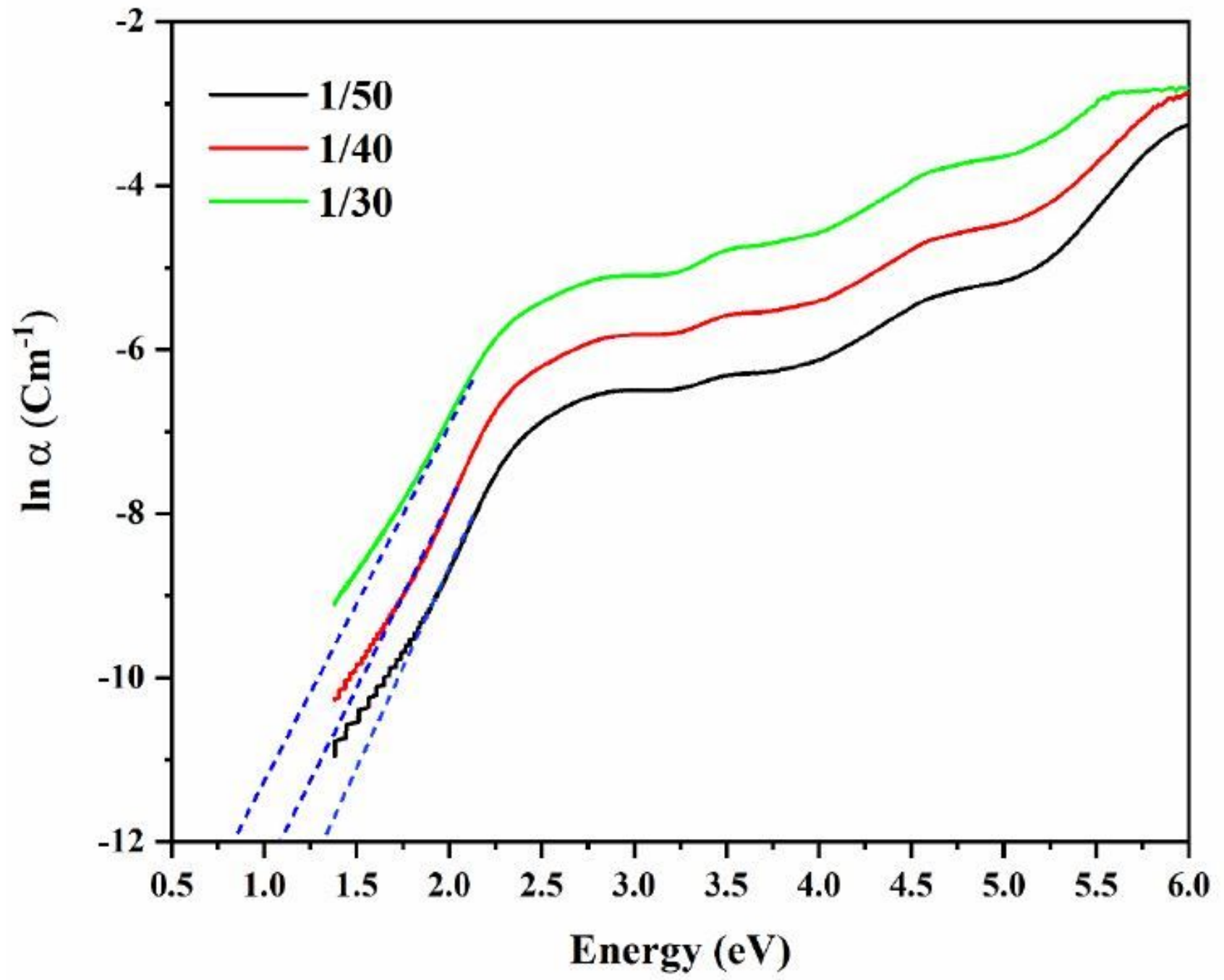

Figure 4

Calculation of Urbach energy for the synthesized Ag/Ag20 


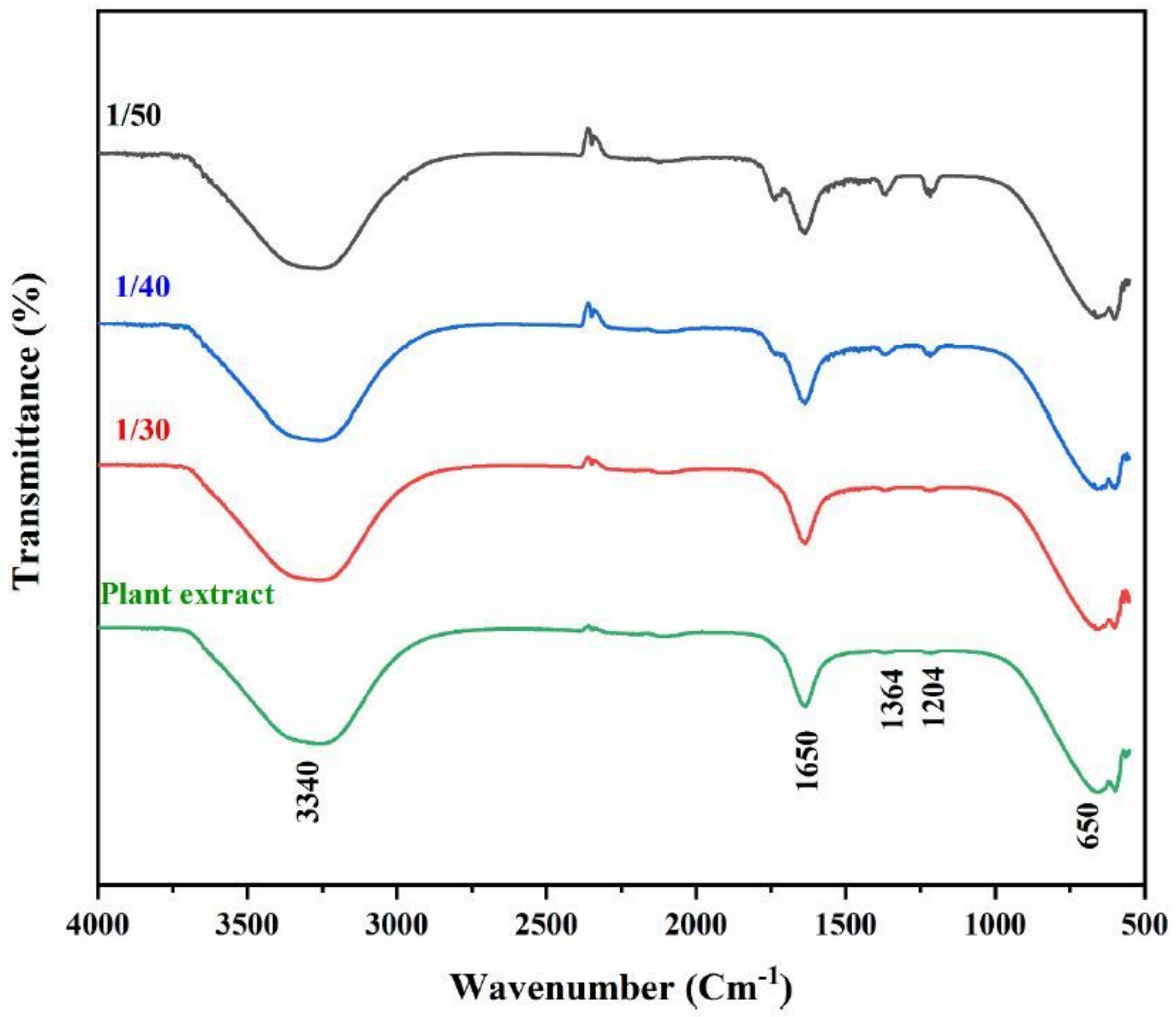

Figure 5

FTIR spectra of Phoenix Dactylifera L extract and the biosynthesized Ag/Ag20. 


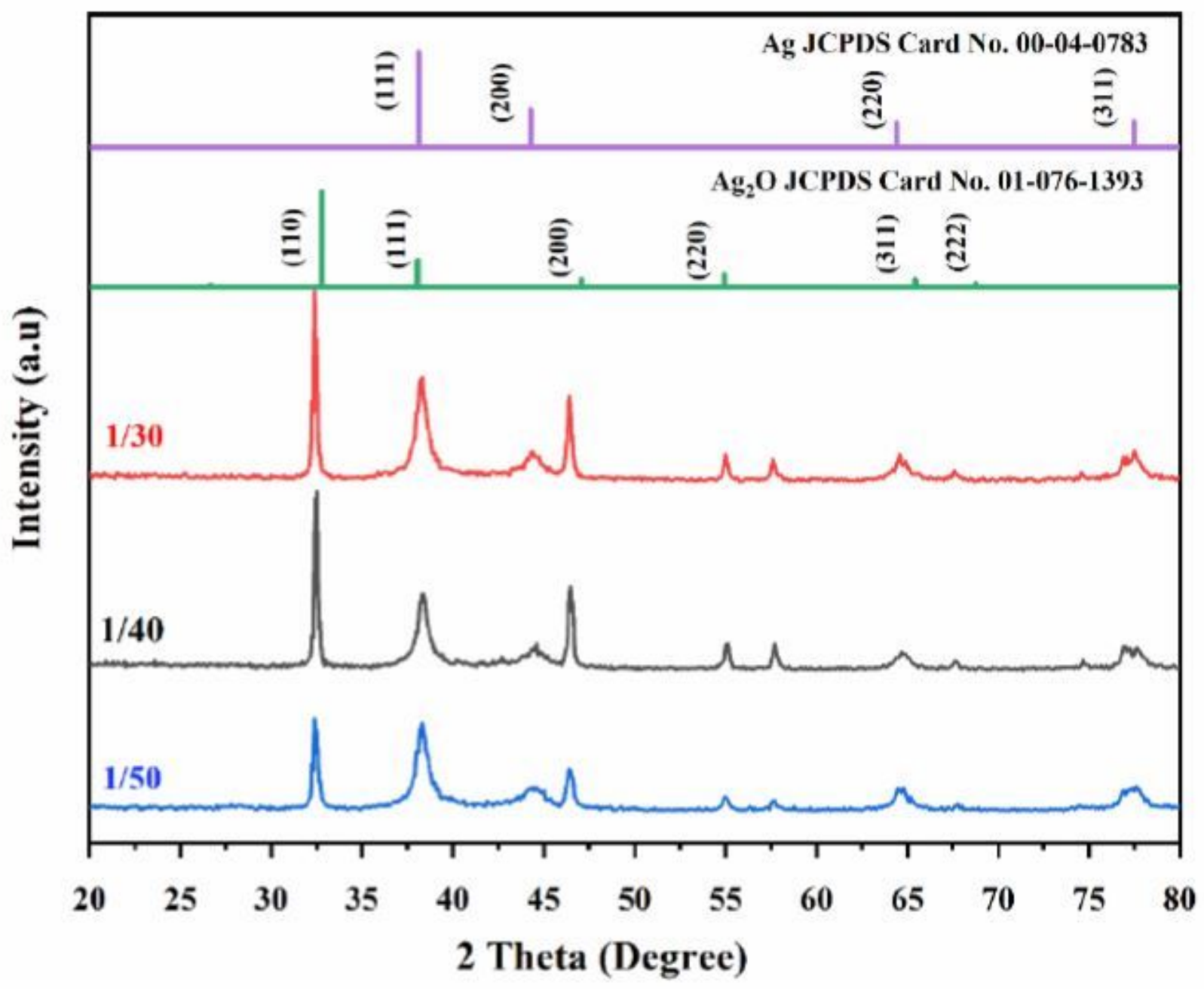

Figure 6

XRD patterns of $\mathrm{Ag} / \mathrm{Ag} 20$ at different volume ratios. 

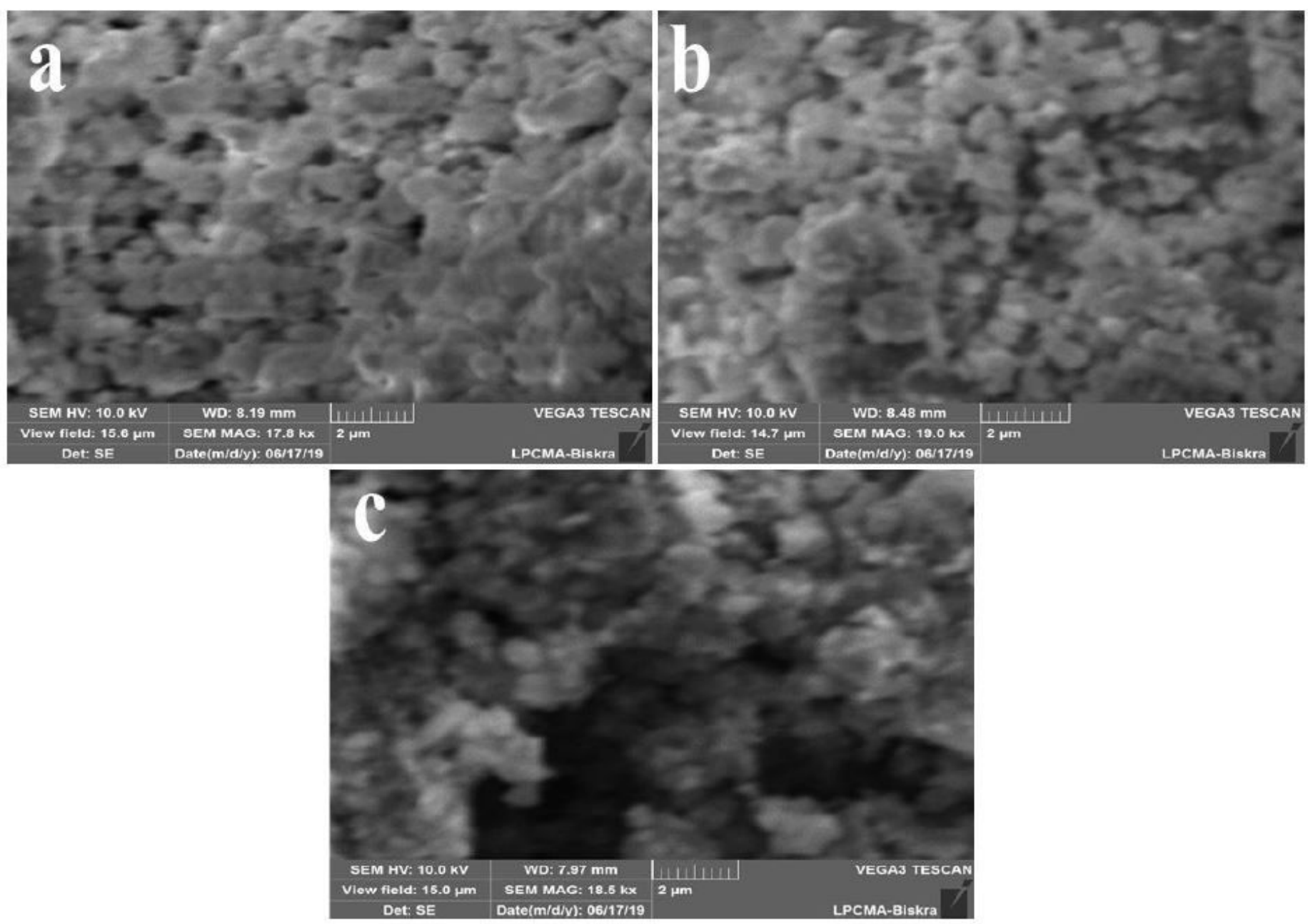

\section{Figure 7}

SEM images of green synthesized Ag/Ag20 nanoparticles with different volume ratios: a) $1 / 30$, b) $1 / 40$, c) $1 / 50$ 


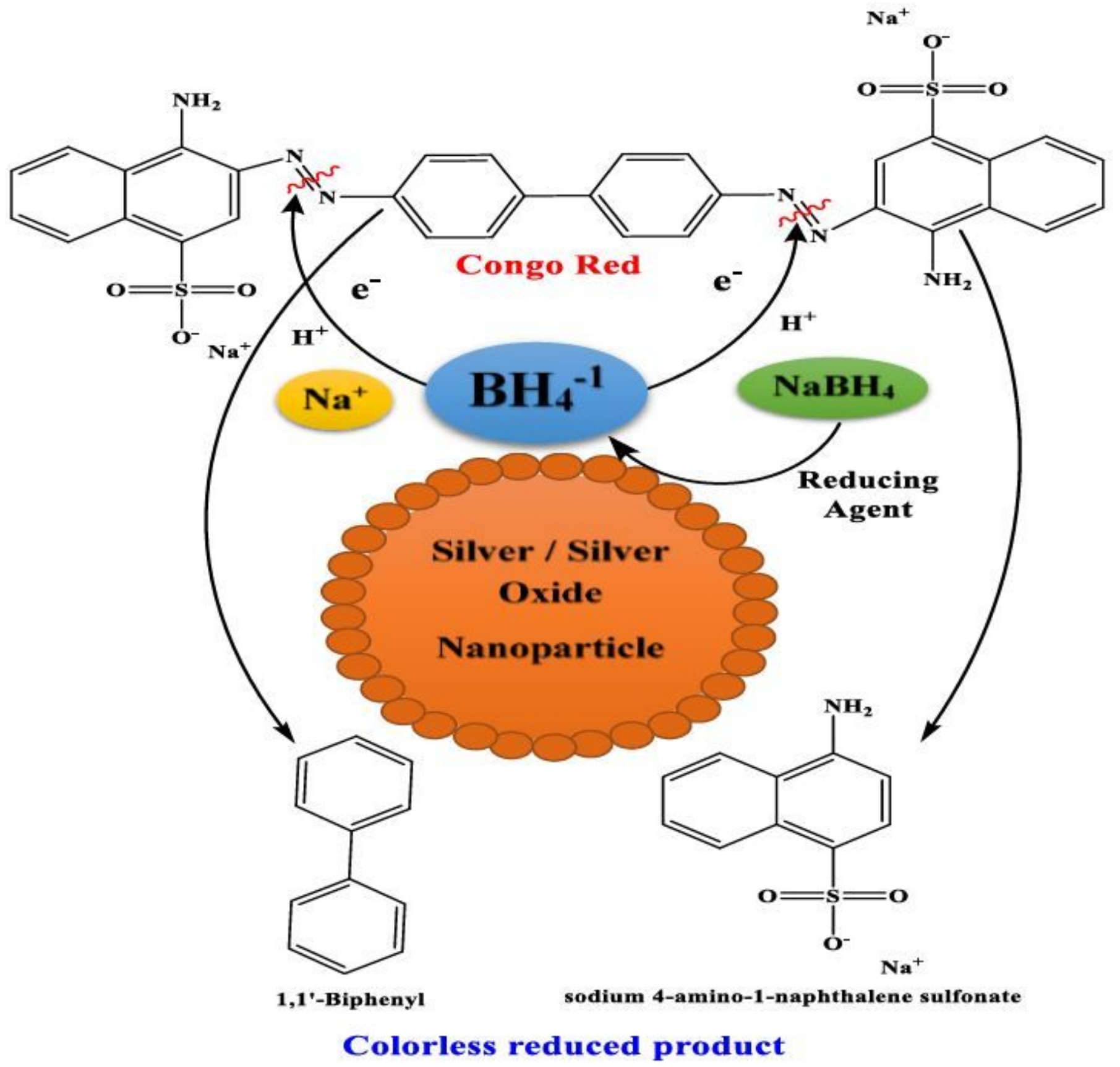

Figure 8

The Proposed mechanism for the silver/silver oxide nanoparticle-catalyzed reduction of CR using $\mathrm{NaBH} 4$ 35 . 


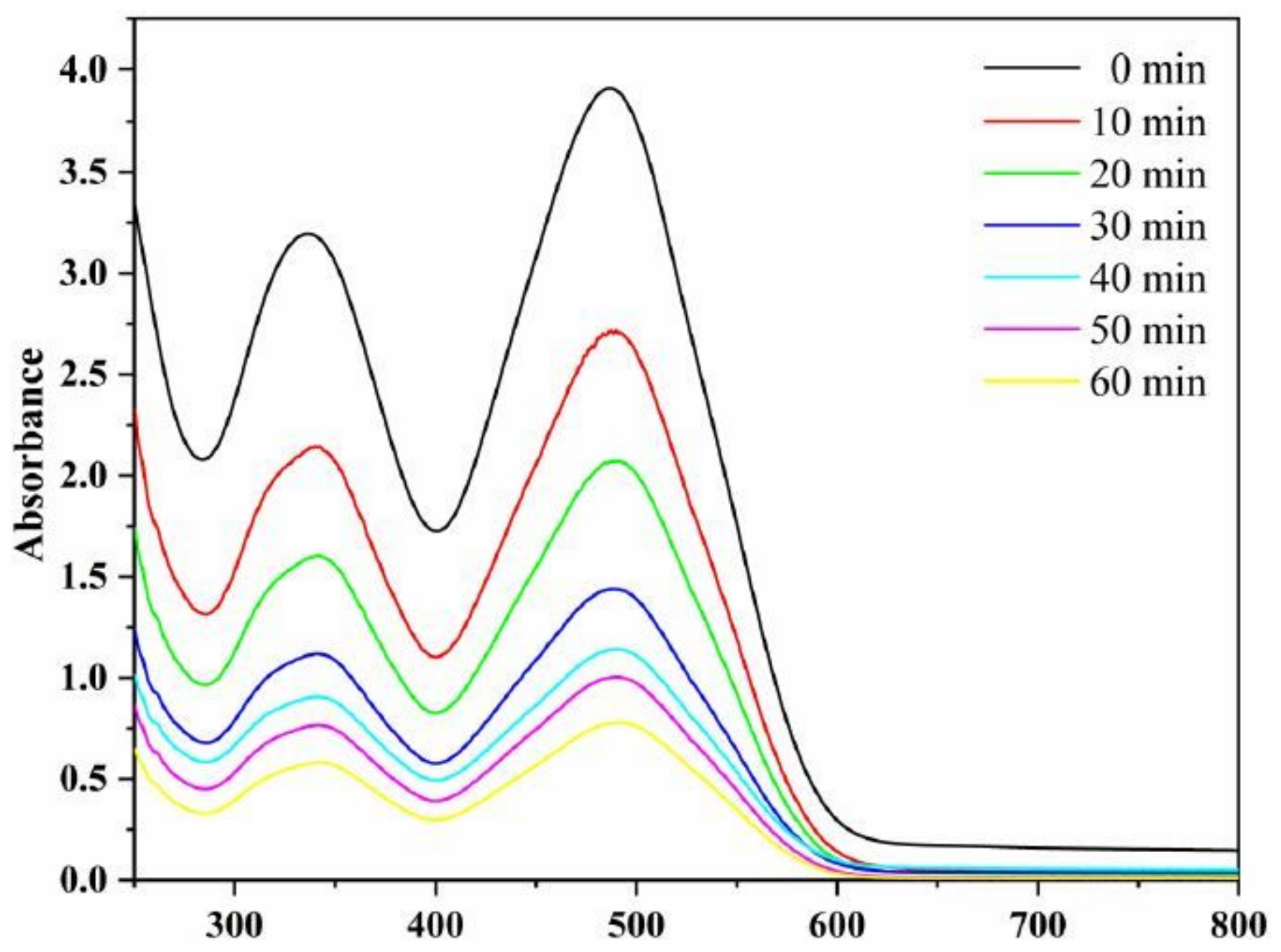

Figure 9

UV-vis spectra versus congo red dye under optimal reaction conditions. 


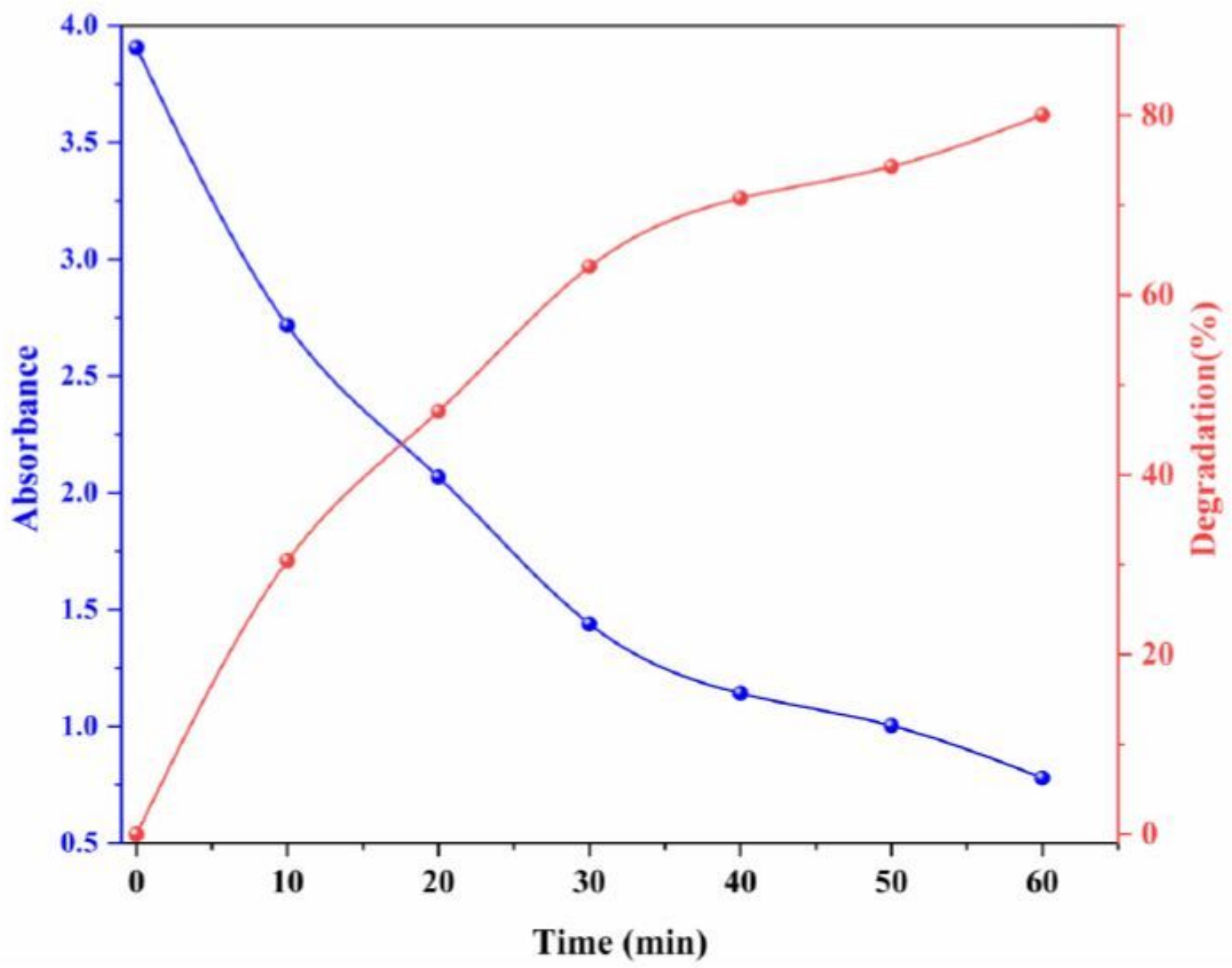

Figure 10

The graph of the decrease in absorbance and height percent of Congo red dye degradation versus time. 


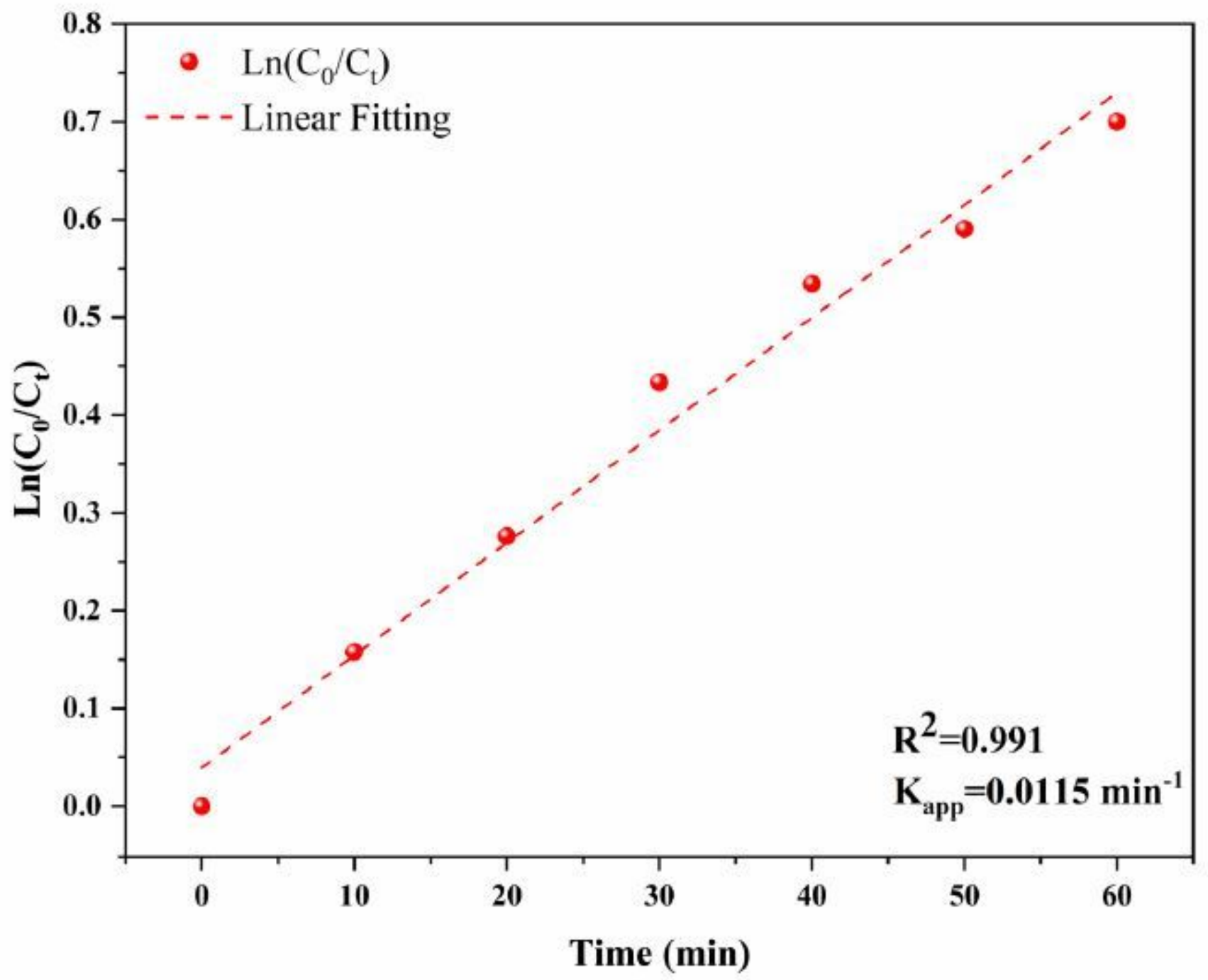

Figure 11

Plot of In (CO/Ct) versus time for the silver / silver oxide nanoparticle-catalysed degradation of Congo red. 


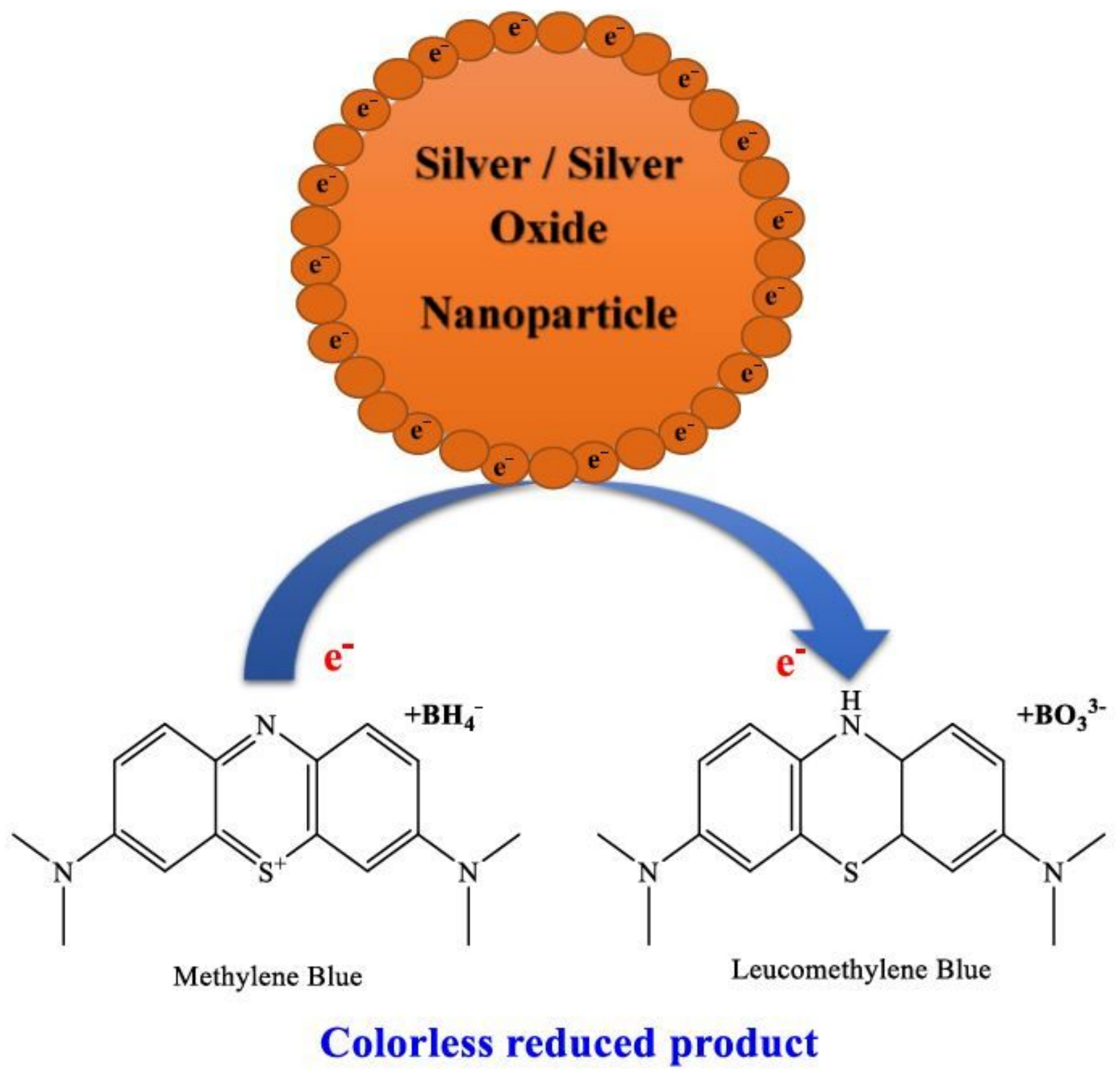

Figure 12

Schematic illustration of the catalytic degradation of MB process by Ag / Ag2O NPs 


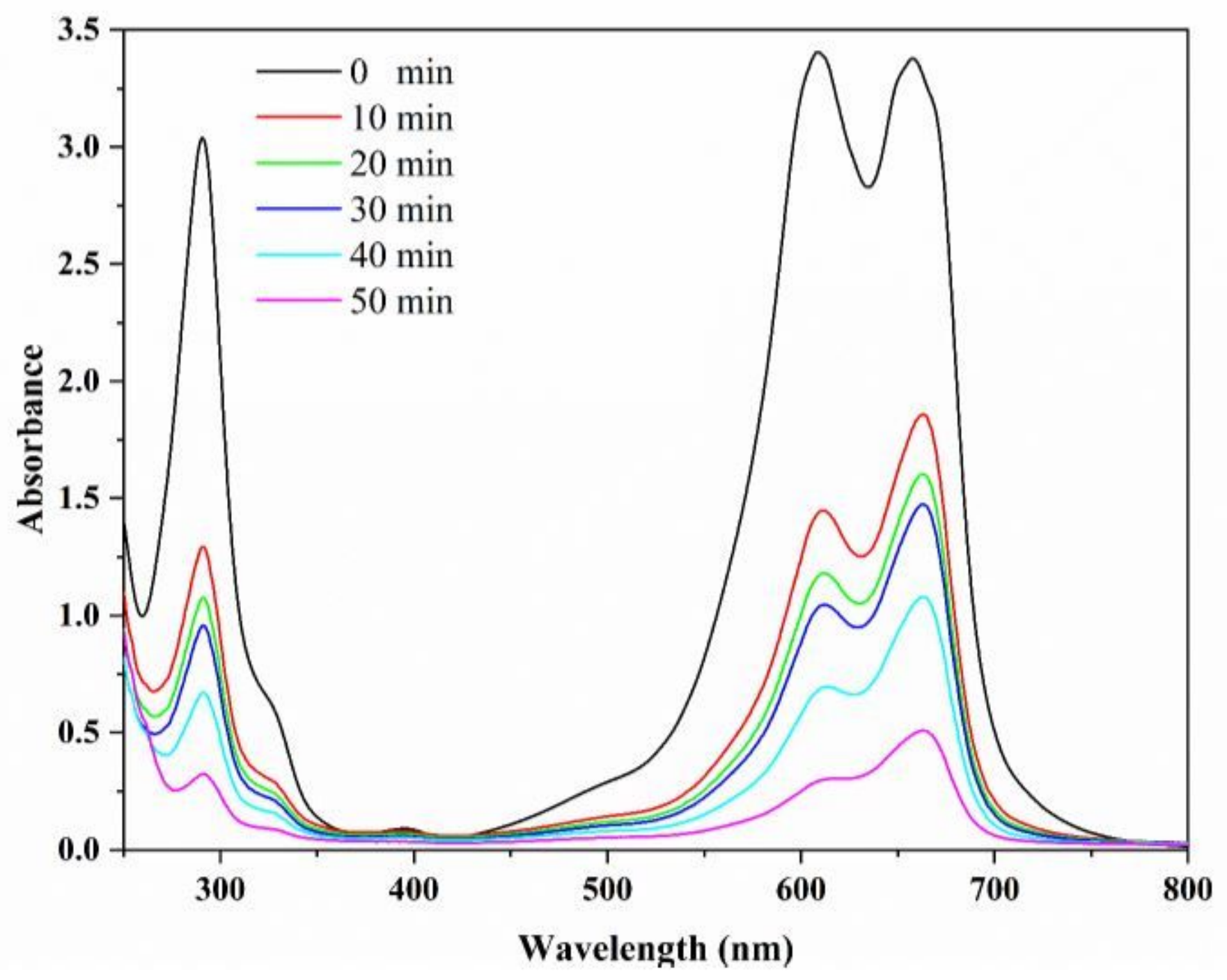

Figure 13

UV-vis spectra for the reduction of MB using Ag/Ag2O NPs 


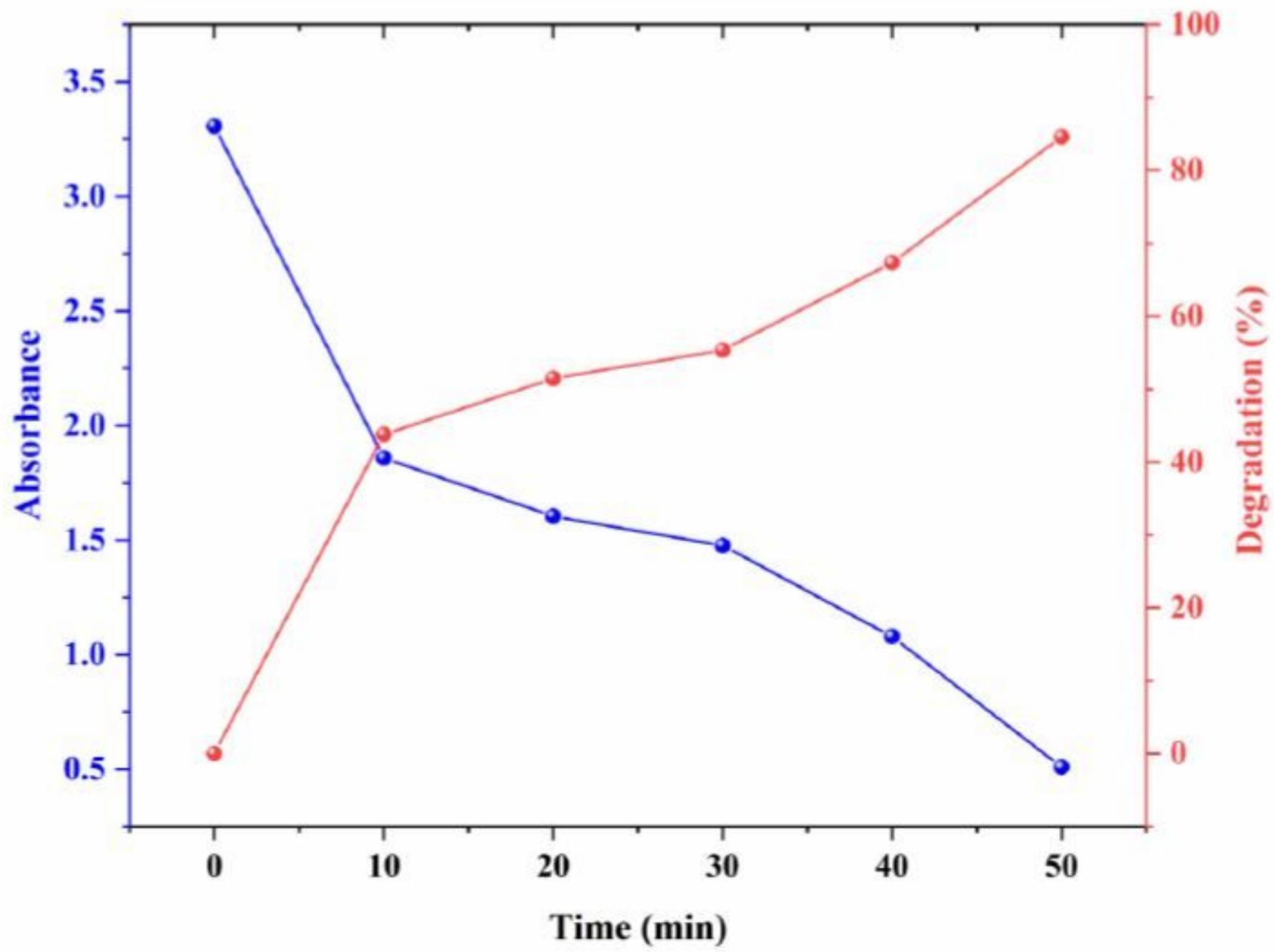

Figure 14

Plot of $\ln (\mathrm{Ct} / \mathrm{CO})$ versus time for the silver / silver oxide nanoparticle-catalysed degradation of Methylene blue. 


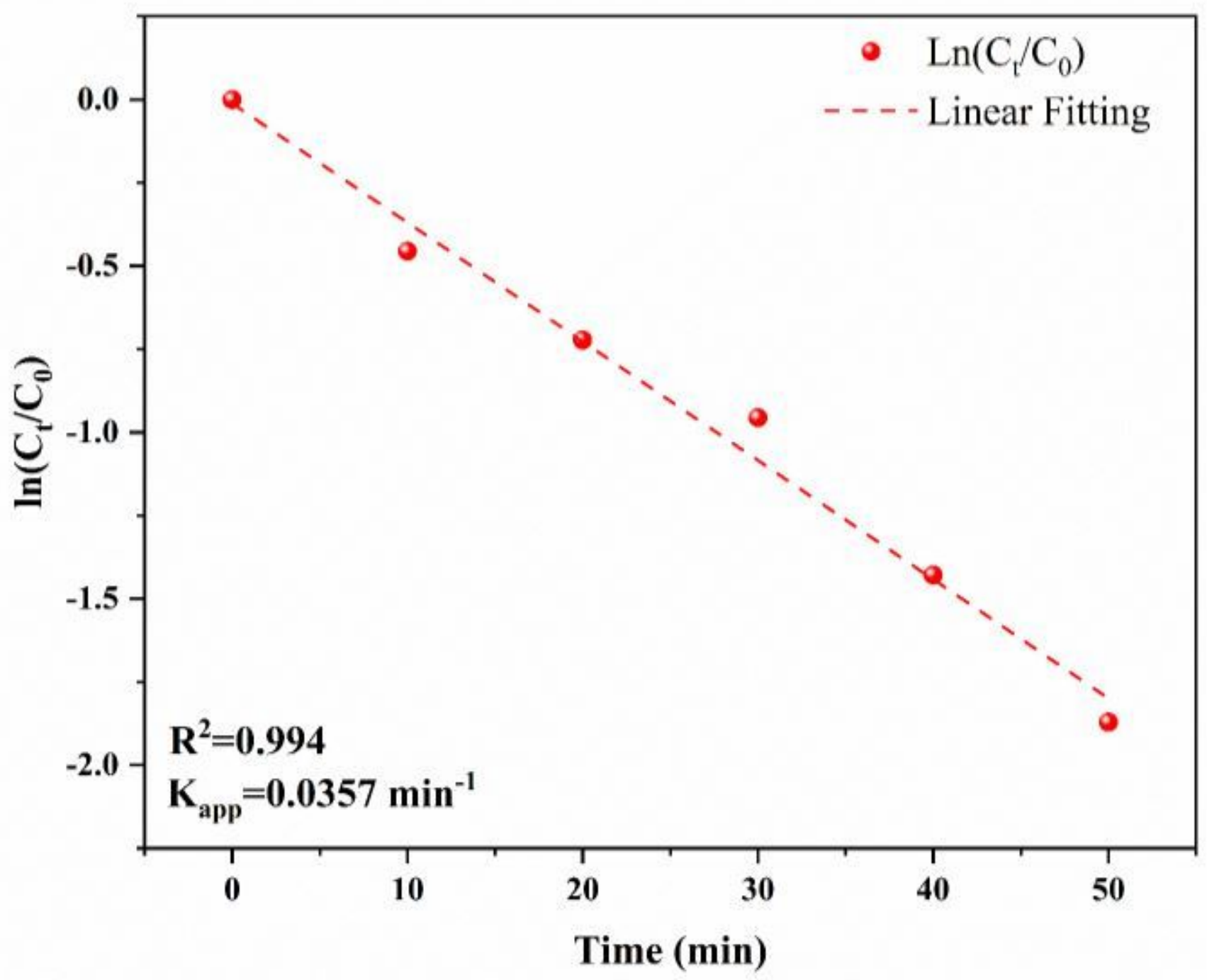

Figure 15

Plot of $\ln (\mathrm{Ct} / \mathrm{CO})$ against reaction time for the catalytic reduction of $\mathrm{MB}$ with $\mathrm{Ag} / \mathrm{Ag} 2 \mathrm{O} \mathrm{NPs}$

\section{Supplementary Files}

This is a list of supplementary files associated with this preprint. Click to download.

- GraphicAbstract.tif 